NBER WORKING PAPER SERIES

\title{
GUNS, DRUGS AND JUVENILE CRIME: \\ EVIDENCE FROM A PANEL OF SIBLINGS AND TWINS
}

\author{
H. Naci Mocan \\ Erdal Tekin \\ Working Paper 9824 \\ http://www.nber.org/papers/w9824 \\ NATIONAL BUREAU OF ECONOMIC RESEARCH \\ 1050 Massachusetts Avenue \\ Cambridge, MA 02138 \\ July 2003
}

We thank Kaj Gittings and Norovsambuu Tumennasan for excellent research assistance, and Donna Stubbs, Robert Kaestner, Mike Grossman, Phil Cook, Steve Levitt, John Donohue and especially Karen Kafadar for helpful suggestions. The views expressed herein are those of the authors and not necessarily those of the National Bureau of Economic Research

(C)2003 by Naci Mocan and Erdal Tekin. All rights reserved. Short sections of text not to exceed two paragraphs, may be quoted without explicit permission provided that full credit including (C notice, is given to the source. 
Guns, Drugs and Juvenile Crime: Evidence from a Panel of Siblings and Twins

Naci Mocan and Erdal Tekin

NBER Working Paper No. 9824

July 2003

JEL No. H0, K4, I12

\section{$\underline{\text { ABSTRACT }}$}

Using a nationally-representative panel data set of U.S. high school students (AddHealth data) that contains a relatively large sample of siblings and twins, the paper investigates the impacts of gun availability at home and individual drug use on robbery, burglary, theft and damaging property for juveniles. Using a variety of fixed-effects models that exploit variations over time, the results show that gun availability at home increases the propensity to committing robbery, burglary and theft by about two percentage points for juveniles but has no impact on damaging property. It is unlikely that gun availability is merely a measure of the unobserved home environment because gun availability does not influence other risky or bad behaviors of juveniles. The results show that having access to guns increases the probability of being cut or stabbed by someone and of someone pulling a knife or gun on the juvenile. Estimates obtained from models that exploit variations over time and between siblings and twins indicate that the median impact of cocaine use on the propensity to commit various types of crimes is 23 percentage points. The impact of using inhalants or other drugs is an increase in the propensity to commit crime by 14 and 18 percentage points, respectively.

H. Naci Mocan

University of Colorado at Denver Department of Economics

Campus Box 181, P.O. Box 173364

Denver, CO 80217-3364

and NBER

nmocan@carbon.cudenver.edu
Erdal Tekin

Georgia State University

Department of Economics

Andrew Young School of Policy

Studies; University Plaza

Atlanta, GA 30303-3083

and NBER

tekin@gsu.edu 
Guns, Drugs and Juvenile Crime: Evidence from a Panel of Siblings and Twins

\section{Introduction}

Despite the decline in juvenile crime since the early 1990s, opinion polls indicate that the public overwhelmingly believes that juvenile crime is a serious problem facing the country (Soler 2001). Investigation of the determinants of juvenile crime is important for a number of reasons. First, the social cost of youth crime is estimated to be $\$ 60$ to $\$ 300$ billion per year, and the overwhelming majority of this cost is an externality to the society (Levitt and Lochner 2001). ${ }^{1}$ Second, participating in illegal activities early in life has implications for the future well-being of the individual. For example, Mocan, Billups and Overland (2000) show that current criminal activity makes future criminal activity more likely by increasing criminal human capital and depreciating legal human capital. Thus, engaging in crime when young would make one less likely to be successful in the legal labor market later in life. Along the same lines, Allgood, Mustard and Warren (1999) show that youth criminal behavior has a negative impact on earnings as an adult, and Bound and Freeman (1992) and Freeman and Rodgers (2000) document a negative relationship between youth criminal record and labor market outcomes.

Levitt and Lochner (2001) present a four-part classification scheme to explain criminal activity, which involves biological, social, criminal-justice system and economic factors. For example, social factors include the extent of parental supervision and behaviors of neighborhood peers (Glaeser, Sacerdote and Scheinkman 1996; Mocan and Rees 1999, 
Case and Katz 1991). The influence of increased punitiveness of the criminal justice system is documented by Levitt (1999), Levitt (1998), Snyder and Sickmund (1999) and Corman and Mocan (2000); and examples of the research on the relationship between economic conditions and crime include Gould, Mustard and Weinberg (2002), Corman and Mocan (2002), Raphael and Winter-Ebmer (2001). ${ }^{2}$

\section{Drugs, Guns and Crime}

Drug use and access to firearms are two other potentially important determinants of criminal activity, although the extent of the relationships between guns and crime, and drugs and crime have not been identified clearly. Despite the strong evidence that drug use and criminal activity are positively correlated, the causal impact of drug use on crime has not been conclusively established (see the literature reviews of Chaiken and Chaiken 1990, Harrison 1992). Even though some recent studies using aggregate data provided evidence on the potential causal impact of drug use on crime (Corman and Mocan 2000, Grogger and Willis 2000), convincing cause-and-effect evidence from micro data is missing. ${ }^{3}$ The difficulty in identifying the causal impact of drug use on crime stems from the possibility that the observed positive correlation between drug use and crime may be due to the influence of an unobserved variable which has an impact on both drug use and criminal activity. For example, if the degree of risk aversion of the individual has an impact on both his drug use

\footnotetext{
${ }^{1}$ Levitt and Lochner (2001) report the upper limit of the social cost of youth crime as $\$ 300$ billion, but they indicate that this may be an overestimate because the typical youth crime is less serious in comparison to an adult crime.

${ }^{2}$ For a more detailed discussion of various factors ranging from schools to gangs, see Wilson and Petersilia (1995).

3 A few papers analyzed micro data in related context. Markowitz (2000) investigated the impact of alcohol and drug prices on violent crime using the National Crime Victimization Survey, Jofre-Bonet and Sindelar (2002) analyzed the impact of drug treatment on criminal behavior.
} 
and criminal behavior, then biased estimates of the impact of drug use on crime would be obtained in analyses that do not take into account the confounding due to risk aversion.

Another contested issue is the link between gun ownership and criminal activity. Blumstein (1995) suggests that the rise in juvenile homicide rate between mid-1980s and early 1990s is associated with an increased tendency to carry guns among juveniles. Wintemute (2000) argues that the increase in violence in mid-1980s is attributable to gun manufacturers' move to produce cheap medium- and high-caliber pistols, and that the decline in youth violence in the 1990s is attributable to stricter gun control policies adopted during the same period. However, empirical evidence on the impact of gun ownership on crime is mixed. In an analysis of the impact of right-to-carry laws, Lott and Mustard (1997) report that counties with concealed weapons laws have lower crime rates, while Duggan (2001) shows that changes in gun ownership are positively related to changes in homicide rates, and that this relationship is driven almost entirely by an impact of gun ownership on homicides with firearms. Cook and Ludwig (2002) find that local gun ownership prevalence has a positive impact on residential burglary rates. They interpret this finding as an indication that the existence of guns at homes may be a motivation for burglars because guns are valuable loot. Ayres and Donohue III (2002) show that the finding of "more guns-less crime" by Lott and Mustard (1997) is not robust to estimation with updated data. On the other hand, Marvell (2001) finds no evidence that juvenile handgun bans adopted by states had any impact on crime. Ludwig and Cook (2000) find no evidence that implementation of the Brady Act was associated with a reduction in homicide rates; and Lott and Whitley (2001) find no evidence that safe-storage gun laws reduce the number of juvenile accidental gun deaths or suicides, and that the passage of the law is associated with increased violent crime 
and more crimes occurring in people's homes. Mustard (2001) finds that enactment of rightto-carry laws does not increase police deaths, and may actually help reduce their risk of being killed.

Based on these conflicting findings, some analysts suggest that gun control laws reduce social welfare, and that they should be scrapped. They claim that this is because research reveals no impact of gun control on crime, while gun control is costly as it interferes with individual choice and imposes monetary costs on police, prosecutors, courts, and prisons (Parker 2001).

The research on gun-crime relationship cited above relies on aggregate (state or county level) data on crime rates. More specifically, analysts investigated the impact of the enactment of concealed weapon laws, or a measure of gun ownership on aggregate crime rates. The main shortcoming of this research is the measurement of gun ownership or gun availability. Gun ownership is approximated by various proxies, such as sales of Guns \& Ammo magazine at the state or county level (Duggan 2001), the proportion of suicides that involve firearms (Cook and Ludwig 2002), and voter-exit surveys (Lott 2000). In this paper we use nationally-representative individual-level data, where information on the availability of guns at home as well as delinquent behavior are provided directly by each respondent. Analyses of aggregate crime data reveal the net impact of gun ownership on crime rates. For example, assume that gun availability increases criminal tendencies, and gun availability also allows opportunities for self-defense, which deters potential perpetrators. The net effect of these factors on crime may be zero. On the other hand, the net effect would again be zero if there was no impact of gun availability on crime either from aggression or protection points of view. It is difficult to isolate these factors using aggregate data. The 
individual-level data set we use allows us to directly test whether gun availability induces juveniles to commit more crime. In addition, using victimization information provided by the same individuals in the data set, we test whether gun availability has an impact on juveniles' crime victimization. Thus, our analysis provides a clearer picture regarding the pathways through which gun ownership impacts crime.

\section{A Panel of Siblings and Twins}

This is the first paper to investigate the link between guns, drug use and juvenile crime using nationally-representative individual-level data. To eliminate confounding due to unobservable variables, we exploit the longitudinal aspect of the data which include siblings and twins who live in the same household. The use of longitudinal data to eliminate timeinvariant individual heterogeneity is a standard tool in micro-econometrics. As explained below in detail, the longitudinal nature of our data, and an unusually large number of personal and family background variables allow us to examine the impact of the availability of guns at home on an individual's criminal activity.

Data on twins have been employed by previous research to estimate returns to education, schooling and marriage decisions, and the impact of birth weight on infant health (Ashenfelter and Krueger 1994; Miller, Mulvey and Martin 1995; Behrman, Rosenzweig and Taubman 1994; Behrman, Rosenzweig and Taubman 1996; Almond, Chay and Lee 2002). All of these twin studies employed cross-sectional data on twins, and to the best of our knowledge, this is the first study that uses a panel of siblings and twins to control for both the impacts of time-invariant and time-varying unobservables. 
We analyze four different crimes: robbery, burglary, damaging property, and theft. The four drug use indicators we employ are the use of cocaine, the use of inhalants, injecting illegal drugs, and the use of other drugs. The information on gun availability is obtained by asking juveniles whether guns are easily available to them at home. We address potential measurement error in drug use and gun availability. The identification of the impact of gun availability on crime is obtained from the change in gun availability between the survey years. Between-sibling variation cannot be exploited to investigate guns-and-crime relationship because all sibling pairs answered the question on gun availability in the same manner. We find that gun availability increases the propensity to commit robbery, burglary and theft for juveniles, but it has no impact on damaging property. Gun availability does not reduce the probability of being victimized, and it makes it more likely for a juvenile to be stabbed or having a knife or gun pulled on him. We show that gun availability is unlikely to be a measure of undesirable home environment, because gun availability has no impact on other bad behavior such as lying, smoking, being expelled from school, drinking and fighting, and having sex.

Drug use is found to increase the propensity to commit crime. Using cocaine, inhalants, and other drugs increases the propensity to commit crime from 14 to 23 percentage points; injecting drugs increases the probability of committing crime by 50 percentage points.

Section II presents the analytical framework, section III discusses the measurement error in drug use. Section IV describes the data, Section V displays the results and Section VI is the conclusion. 


\section{Analytical Framework}

The crime supply equation, with the addition of drug use and guns can be presented as: ${ }^{4}$

(1) $\mathrm{CR}=\mathrm{f}(\mathrm{X}, \mathrm{A}, \mathrm{F}, \mathrm{DR}, \mathrm{G})$,

where CR stands for a measure of the extent of the criminal activity of the individual, $X$ represents the characteristics of the person such as age, race and ethnicity and religious beliefs. $A$ stands for location-specific deterrence and economic variables that impact criminal involvement, such as crime-specific arrest rates, police presence, and the unemployment rate, $F$ is a vector of parent and family characteristics, $D R$ represents drug use of the individual, and $G$ stands for the availability of guns to the individual. ${ }^{5}$

Drug consumption in Equation (1) is a function of the price of drugs, buyers' income, and tastes for drug use and specific penalties targeted at drug users. Using Goldstein's (1985) conceptual framework, drug use can affect criminal activity through three channels.

First, the "pharmacological" effect is the direct impact of drug use on criminal activity because drug use may increase aggression. The second is the "economic" effect— that higher expenditures on drugs cause some users to finance these expenditures by committing crime. The third is the "systemic" effect — the violence due to the illegality of the drug market, because the participants cannot rely on contracts and courts to resolve disputes. If the "economic" effect is the dominant factor to influence criminal activity, the impact of drug use on crime could be ambiguous. For example, if the demand for drugs is price inelastic, then an

\footnotetext{
${ }^{4}$ Theoretical justification of the inclusion of drug use in the crime equation can be found, among others, in Ehrlich (1973).

${ }^{5}$ Empirical evidence from aggregate data on the impact on crime of deterrence, economic conditions and drug use can be found, among others, in Corman and Mocan (2002), Corman and Mocan (2000), Levitt (1998), Levitt (1999), and Raphael and Winter-Ebmer (2001).
} 
increase in drug use, say due to a rightward shift of the supply of drugs, would be associated with an increase in drug consumption which is coupled with a decrease in drug spending. If the economic effect is more important than the pharmacological one, increased drug use would be associated with a reduction in crime. ${ }^{6}$

Ownership of guns can impact crime in two different ways. First, gun ownership may make committing crime, especially violent crime, easier. Second, gun ownership may prevent crime victimization if potential perpetrators consider the probability that their victim may carry a gun. In our particular case, we analyze these two effects separately. That is, we investigate both the tendency to commit crime and the likelihood of being a victim of a crime of the same individuals as a function of gun availability at their home.

Empirical specification of the crime supply equation as a function of observable and unobservable personal characteristics (including biological attributes), deterrence measures, economic conditions, as well as the attributes of the family, the extent of the drug use of the individual and the availability of guns is presented by Equation (2) below.

$$
\mathrm{CR}_{\mathrm{jit}}=\alpha+\delta \mathrm{X}_{\mathrm{jit}}+\gamma \mathrm{F}_{\mathrm{jit}}+\beta \mathrm{DR}_{\mathrm{jit}}+\varphi \mathrm{G}_{\mathrm{jit}}+\varsigma \mathrm{A}_{\mathrm{st}}+\mu_{\mathrm{ji}}+\lambda_{\mathrm{jit}}+\Omega_{\mathrm{ji}}{ }^{\mathrm{F}}+\Psi_{\mathrm{jit}}{ }^{\mathrm{F}}+\varepsilon_{\mathrm{jit}}
$$

where $\mathrm{CR}_{\mathrm{jit}}$ is the criminal activity measure of the $i$ th individual of the $j$ th sibling (or twin) pair at time $t . X_{j i t}$ represents observable individual characteristics such as age, race, gender and religiosity of the person, weekly allowance of the child, and measures of risk aversion such as whether the child wears seatbelt while driving. $F_{j i t}$ stands for observable family

\footnotetext{
${ }^{6}$ For a more detailed discussion, see Mocan and Corman (1998).
} 
attributes, including parent characteristics and measures of the extent of supervision at home. ${ }^{7}$ $D R_{j i t}$ represents consumption of drugs, and $G_{j i t}$ is the availability of guns at home. $A_{s t}$ stands for the deterrence measures faced by the individual, such as the arrest rates and the size of the police force, as well as local economic conditions in location $s$ at time $t$ where the child resides, and $\mu_{\mathrm{ji}}$ captures individual-specific time-invariant unobservables which include intellect. $\lambda_{\mathrm{jit}}$ represents person-specific time-varying unobservables, $\Omega_{\mathrm{ji}}{ }^{\mathrm{F}}$ captures unobservable time-invariant family attributes, $\Psi_{\mathrm{jit}}{ }^{\mathrm{F}}$ is unobservable time-varying family attributes, and $\varepsilon_{\mathrm{jit}}$ is a standard error term.

Taking the first-difference of Equation (2) across time periods gives

$$
\Delta \mathrm{CR}_{\mathrm{jit}}=\delta \Delta \mathrm{X}_{\mathrm{jit}}+\gamma \Delta \mathrm{F}_{\mathrm{jit}}+\beta \Delta \mathrm{DR}_{\mathrm{jit}}+\varphi \Delta \mathrm{G}_{\mathrm{jit}}+\varsigma \Delta \mathrm{A}_{\mathrm{st}}+\Delta \lambda_{\mathrm{jit}}+\Delta \Psi_{\mathrm{jit}}^{\mathrm{F}}+\Delta \varepsilon_{\mathrm{jit}}
$$

where $\Delta$ stands for time-differencing. Equation (3) is a standard fixed-effects model, where time-invariant family and individual characteristics drop out, but time-varying heterogeneity remains.

We estimate different formulations of Equation (3) to investigate the link between gun availability at home (G) and juvenile's criminal activity. Note that in Equation (3), the change in individual's criminal activity between the two years depends, among other factors, on the change in local deterrence and economics variables $\left(\mathrm{A}_{\mathrm{st}}\right)$. The values of these variables are not collected beyond the first year of our data; therefore $\Delta \mathrm{A}_{\mathrm{st}}$ cannot be calculated. However, following Currie and Moretti (2002) and Cook and Ludwig (2002), we include state or county dummies to control for such factors. That is, we estimate

\footnotetext{
${ }^{7}$ The complete list of these variables is given in the data section below.
} 


$$
\Delta \mathrm{CR}_{\mathrm{jit}}=\delta \Delta \mathrm{X}_{\mathrm{jit}}+\gamma \Delta \mathrm{F}_{\mathrm{jit}}+\beta \Delta \mathrm{DR}_{\mathrm{jit}}+\varphi \Delta \mathrm{G}_{\mathrm{jit}}+\kappa \mathrm{K}_{\mathrm{s}}+\mathrm{e}_{\mathrm{jit}}
$$

where $K_{s}$ stands for a set of state or county dummies that control for state-specific or countyspecific time-varying local deterrence and economic factors, and $e$ is the error term.

As summarized in Duggan (2001), it is conceivable that a positive relationship between gun ownership and crime may indicate purchase of guns in response to expected future increases in crime. Although this argument has merit, especially in aggregate data, Duggan (2001) finds no support of such reverse causality from expected crime to gun ownership. In our case reverse causality is even less likely. This is because, our dependent variable is criminal activity of the youth, while our gun measure is the availability of guns at home. To the extent that this measure captures guns owned by parents, it is exogenous to future criminal involvement of the child. On the other hand, if parents' gun ownership is a proxy of their criminal propensity, and if this attribute is transmitted to the child, then gun availability at home is a proxy of bad home environment, which may be correlated with juvenile's delinquent behavior. We show in the results section that this hypothesis has no empirical support.

Unlike gun availability at home, consumption of illicit drugs varies between siblings. This allows us to eliminate time-varying family effects by taking within-sibling differences of Equation (3), which gives: ${ }^{8}$

(4) $\nabla \Delta \mathrm{CR}_{\mathrm{jit}}=\delta \nabla \Delta \mathrm{X}_{\mathrm{jit}}+\beta \nabla \Delta \mathrm{DR}_{\mathrm{jit}}+\nabla \Delta \lambda_{\mathrm{jit}}+\nabla \Delta \varepsilon_{\mathrm{jit}}$

\footnotetext{
${ }^{8}$ Note that this procedure also eliminates time-varying economic and deterrence measures as they do not exhibit variation between the individuals in the same household. Subjective probabilities of
} 
where $\nabla$ stands for between-sibling differencing. This specification eliminates all heterogeneity with the exception of time-varying individual-specific unobservables $\left(\lambda_{\mathrm{jit}}\right)$. Note that the family environment and location-specific economic and deterrence variables drop out in Equation (4) as they are the same for all siblings of the same household. The analog of Equation (4) for twins is:

\section{(5) $\nabla \Delta \mathrm{CR}_{\mathrm{jit}}=\delta \nabla \Delta \mathrm{X}_{\mathrm{jit}}+\beta \nabla \Delta \mathrm{DR}_{\mathrm{jit}}+\nabla \Delta \varepsilon_{\mathrm{jit}}$}

In Equation (5) time-varying individual-specific heterogeneity is eliminated under the assumption that it is biologically the same between twins. This may be particularly the case for monozygotic (identical, or MZ) twins. Therefore, Equation (5) is estimated for all twins (monozygotic and fraternal), as well as for MZ twins.

\section{$\underline{\text { III. Measurement Error }}$}

As described in Section IV below, data collection procedures were designed to minimize concern about confidentiality. For example, respondents were not provided with written questionnaires; rather they listened to sensitive questions on delinquent behavior, drug use and gun availability through earphones, and entered their answers directly on laptop computers. Nevertheless, it is still conceivable that drug use and gun availability is reported with error. Furthermore, it is plausible that the reporting error is not symmetric in the classical sense, but it is one-sided.

apprehension and conviction may differ between siblings. However, to the extent that they are approximated by such measures as arrest and conviction rates in the locality, they do not vary. 
To demonstrate the impact of non-random measurement error in drug use in firstdifferenced data, consider equation (6) below where $i$ stands for the ith individual and $t$ is the time period.

(6) $\Delta \mathrm{CR}_{i t}=\beta \Delta D R^{*}{ }_{i t}+\Delta \varepsilon_{i t}$

The subscript $j$ and $\mathrm{X}_{\mathrm{it}}$ are dropped for ease of exposition. Let $\mathrm{DR}_{\mathrm{it}}{ }^{*}$ be the actual drug use, $\mathrm{DR}_{\mathrm{it}}$ stand for the reported drug use and $v_{\mathrm{it}}$ represent the measurement error. The reported drug use is equal to the actual drug use plus the measurement error; that is $\mathrm{DR}_{\mathrm{it}}=\mathrm{DR}^{*}{ }_{\mathrm{it}}+\mathrm{v}_{\mathrm{it}}$.

Note that $\mathrm{DR}=1$ if the individual reports using drugs, and $\mathrm{DR}=0$ if he/she reports no drug use. Similarly, $\mathrm{DR}^{*}=1$ if the actual drug use is positive and $\mathrm{DR}^{*}=0$ if actual drug use is zero. Let the probability distribution of $v_{\text {it }}$ be $\operatorname{Prob}\left(\mathrm{DR}_{\mathrm{it}}=1, \mathrm{DR}_{\mathrm{it}}^{*}=1\right)=\mathrm{p}_{1}, \operatorname{Prob}\left(\mathrm{DR}_{\mathrm{it}}=1, \mathrm{DR}_{\mathrm{it}}^{*}=0\right)=0, \operatorname{Prob}\left(\mathrm{DR}_{\mathrm{it}}=0, \mathrm{DR}_{\mathrm{it}}^{*}=0\right)=\mathrm{p}_{2}$, $\operatorname{Prob}\left(\mathrm{DR}_{\mathrm{it}}=0, \mathrm{DR}_{\mathrm{it}}^{*}=1\right)=\mathrm{q}$.

That is,

\begin{tabular}{|c|c|c|c|}
\hline $\mathrm{DR}_{\text {it }}$ & $\mathrm{DR}^{*}{ }_{\text {it }}$ & $\mathrm{v}_{\text {it }}$ & $\operatorname{Prob}\left(\mathrm{v}_{\mathrm{it}}\right)$ \\
\hline 1 & 1 & 0 & $\mathrm{P}_{1}$ \\
\hline 1 & 0 & 1 & 0 \\
\hline 0 & 0 & 0 & $\mathrm{P}_{2}$ \\
\hline 0 & 1 & -1 & $\mathrm{q}$ \\
\hline
\end{tabular}

The first row in the table indicates that the probability of using drugs and reporting as such is $p_{1}$. The second row indicates that the probability of reporting positive drug use when the person in fact did not use drugs is zero. The probability of telling the truth when actual drug use is zero is $\mathrm{p}_{2}$; and $\mathrm{q}$ stands for the probability of lying when the actual drug use is positive. 
The estimated $\beta$ in Equation (6) is equal to

$$
\hat{\beta}_{\Delta}=\frac{\sum_{i} \Delta D R_{i t} \Delta C R_{i t}}{\Sigma_{i} \Delta D R_{i t}^{2}}=\frac{\Sigma\left(\Delta D R_{i t}^{*}+\Delta v_{i t}\right)\left(\Delta D R_{i t}^{*} \beta+\Delta \varepsilon_{i t}\right)}{\Sigma \Delta D R_{i t}{ }^{2}} .
$$

Simplifying and taking the probability limit gives

$p \lim \hat{\beta}=\beta \frac{\operatorname{var}\left[\Delta D R^{*}\right]+\operatorname{cov}\left[\Delta v, \Delta D R^{*}\right]}{\operatorname{var}[\Delta D R]}$

It can be shown that (see Appendix-A)

$$
p \lim \hat{\beta}=\beta\left[\frac{p_{1} p_{2}}{\left(p_{1}-p_{1}^{2}\right)(1-\rho)}\right]
$$

where $\rho$ is the autocorrelation coefficient of reported drug use between the time periods.

(i.e., $\rho=\operatorname{Cov}\left(D_{\text {it }}, D_{i t-1}\right) / \operatorname{Var}\left(D^{i t}\right)$ assuming a covariance-stationary process for $D R$ )

Following Ashenfelter and Zimmerman (1997), the probability limit of $\beta$ in equation (7) can be substituted into Equation (6) to obtain

$$
\Delta C R_{i t}=\beta\left[\frac{p_{1} p_{2}}{\left(p_{1}-p_{1}^{2}\right)(1-\rho)}\right] \Delta D R_{i t}+\Delta \varepsilon_{i t}
$$

Note that $p_{1}$ is readily available in the data, which is the mean reported drug use. The medical literature contains detailed information regarding the reliability of self-reported substance use. For example, in an analysis the drinking patterns of college students, it has been found that the reliability of reporting in the quantity and frequency of drinking beer, 
wine and spirits was high, with a reliability ratio of $0.84 .^{9}$ Reliability ratios range from 0.89 to 0.92 for items such as "driven a car while drinking," "missed a class because of hangover," and "damaged property because of drinking." (Weiss et al., 1998). An analysis of out-oftreatment drug users indicated a reliability ratio of 0.72 for self-reported cocaine use, 0.77 for heroin, and 0.82 for crack. The ratio was 0.88 for the number of times the person injected drugs. For both cocaine and opiate use, total agreement between self-reports and urinalysis was over 84 percent (Johnson et al. 2000). Utilizing this literature, we postulate that $80 \%$ of drug users reported their drug use correctly. This suggests that $\mathrm{p}_{2}=1-\left(\mathrm{p}_{1} / 0.8\right), \mathrm{q}=\mathrm{p}_{1} / 4$, and $\rho$ is calculated from the data, separately for gun availability and each drug use measure. Variations in the reporting rate did not change the results in a meaningful way.

The analysis of guns-crime relationship is performed by estimating versions of Equation (3A). In case of the variable that measures gun availability, measurement error seems negligible. This is because, in the sample of siblings and twins, there is nearly perfect agreement between siblings to the question on gun availability at home. For example, in the first wave among 2,117 sibling pairs, 440 pairs indicated that guns were available to them at home and 1,677 pairs said guns were not available. There was perfect agreement between siblings in these answers. In wave two, 326 individuals indicated that guns were available at home; and 323 of these siblings indicated the same. Thus, the agreement rate was $99 \%$. Onethousand-eighthundred-one juveniles indicated that guns were not available, and the responses of their siblings were almost identical (1,798 of them also said that guns were not

\footnotetext{
${ }^{9}$ The reliability ratio is the proportion of individuals who are confirmed to have provided correct information about their drug use. Confirmation is typically based on drug tests.
} 
available at home). ${ }^{10}$ Therefore, we first report the results with no adjustment for measurement error in gun availability. However, we also report estimates with adjustment for non-random measurement error in gun availability as described above (Equation 8). It is well-known that classical measurement error in the explanatory variable attenuates its estimated coefficient, and the bias is exacerbated in first-differenced data (Levitt 1998a, Griliches and Hausman 1986). ${ }^{11}$ In our case, where we entertain the possibility of one-sided measurement error due to differential propensity of telling the truth about gun availability at home, the bias depends on $\mathrm{p}_{1}, \mathrm{p}_{2}$ and $\rho$.

In models that employ time and sibling (or twin) differencing, we estimate models (suppressing $\mathrm{X}$ ) such as

$$
\nabla \Delta \mathrm{CR}_{j i t}=\beta \nabla \Delta D R^{*}{ }_{j i t}+\nabla \Delta \varepsilon_{j i t}
$$

The probability limit of the estimated coefficient is equal to (the details are in Appendix-A)

$$
\begin{aligned}
& p \lim \hat{\beta}=\beta\left[\frac{4 p_{1} p_{2}}{\left(p_{1}-p_{1}^{2}\right)(4+\Phi)}\right] \\
& \text { where } \Phi=2\left(-\rho_{D R_{j 22} D R_{j 21}}-\rho_{D R_{j 22} D R_{j 12}}+\rho_{D R_{j 22} D R_{j 11}}+\rho_{D R_{j 21} D R_{j 12}}-\rho_{D R_{j 21} D R_{j 11}}-\rho_{D R_{j 12} D R_{j 11}}\right) .
\end{aligned}
$$

\footnotetext{
${ }^{10}$ This cannot be attributable to siblings lying in concert, because although in some cases the siblings took the survey in different days, in most cases they took it simultaneously.

${ }^{11}$ This can be seen by calculating the probability limit of $\varphi$ in equation (3A) when gun availability is measured with error. In case of classical measurement error one obtains

$$
\operatorname{plim} \hat{\varphi}_{\Delta}=\varphi\left[1-\frac{\sigma_{v}^{2}}{\left(\sigma_{G^{*}}^{2}+\sigma_{v}^{2}\right)(1-\rho)}\right]=\varphi\left[1-\frac{\sigma_{v}^{2}}{\sigma_{G}^{2}(1-\rho)}\right]=\varphi\left[1-\frac{1}{\left(\frac{\sigma_{G}^{2}}{\sigma_{v}^{2}}\right)(1-\rho)}\right]
$$
}

where $\rho$ is the observed correlation of reported gun availability at home between time periods one and two. 
$\Phi$ is calculated from reported drug use as it depends on observed correlations in reported drug use over time and between siblings or twins. Thus, in models with time-and-sibling (or twin differencing) we estimate

$$
\nabla \Delta C R_{j i t}=\beta\left[\frac{4 p_{1} p_{2}}{\left(p_{1}-p_{1}^{2}\right)(4+\Phi)}\right] \nabla \Delta D R_{j i t}+\nabla \Delta X_{j i t} \delta+\nabla \Delta \varepsilon_{j i t}
$$

\section{Data}

The data used in the analyses are drawn from the two waves of the National Longitudinal Study of Adolescent Health (Add Health). ${ }^{12}$ Add Health is a nationally representative study of adolescents in grades 7 through 12. An in-school questionnaire was administered to every student who attended one of the sampled 132 U.S. schools on a particular day during the period between September 1994 and April 1995. A random sample of approximately 200 adolescents from each high school/feeder school pair was selected for in-home interviews which are conducted from April 1995 to December 1995. ${ }^{13}$ The in-home

\footnotetext{
${ }^{12}$ The Add Health project is a program project designed by J. Richard Udry (PI) and Peter Bearman, and funded by grant P01-HD31921 from the National Institute of Child Health and Human Development to the Carolina Population Center, University of North Carolina at Chapel Hill, with cooperative funding participation by the National Cancer Institute; the National Institute of Alcohol Abuse and Alcoholism; the National Institute on Deafness and Other Communication Disorders; the National Institute on Drug Abuse; the National Institute of General Medical Sciences; the National Institute of Mental Health; the National Institute of Nursing Research; the Office of AIDS Research, NIH; the Office of Behavior and Social Science Research, NIH; the Office of the Director, NIH; the Office of Research on Women's Health, NIH; the Office of Population Affairs, DHHS; the National Center for Health Statistics, Centers for Disease Control and Prevention, DHHS; the Office of Minority Health, Centers for Disease Control and Prevention, DHHS; the Office of Minority Health, Office of Public Health and Science, DHHS; the Office of the Assistant Secretary for Planning and Evaluation, DHHS; and the National Science Foundation. Persons interested in obtaining data files from The National Longitudinal Study of Adolescent Health should contact Add Health Project, Carolina Population Center, 123 West Franklin Street, Chapel Hill, NC 27516-2524 (email: addhealth@unc.edu).

${ }^{13}$ Participating high schools were asked to identify junior high or middle schools that were expected to provide at least five students to the entering class of the high school. These schools are called
} 
interviews constituted the core sample and contained about 12,000 adolescents. In addition to the core sample, several special samples (e.g. ethnic and genetic) were also drawn on the basis of in-school interviews. The core and the special samples provide a total number 20,745 adolescents for Wave I. The adolescents are interviewed for the second time from April to August 1996 for Wave II. In Wave II, 14,738 adolescents were interviewed. ${ }^{14}$ Data are gathered from adolescents, from their parents, siblings, friends, romantic partners and fellow students, and from school administrators. The survey was designed to provide detailed information on teen behavior, including their criminal and substance use/abuse.

One feature of Add Health that we utilize in this paper is the genetic oversample. The genetic sample consists of pairs of siblings (full, half and stepsiblings), identical twins and fraternal twins. Eligibility for the genetic sample was determined based on the responses provided by adolescents in the in-school questionnaire. All mixed sex twin pairs were classified as fraternal, or dizygotic (DZ). In addition to asking each twin if they were MZ or DZ, each twin was also given a set of questions on confusability of appearance (if they looked like two peas in a pod as young children, and three questions on whether they are confused by strangers, teachers or family members). A zygosity scale is created, which is an average of the confusability item scores over the reports of both twins. When self-report data on appearance was missing, mother's report of confusability of appearance was used. If there was conflict between the twins' self-reports of zygosity and the classification based on

feeder schools. Their probability of selection was proportional to the percentage of the high school's entering class that came from that feeder.

${ }^{14}$ The sample for the Wave II In-home Interview was composed of the respondents of the Wave I Inhome Interview, with the following exceptions: A respondent who was in the 12th grade in Wave I and who was not part of the genetic sample was not interviewed in Wave II. Respondents who were only in Wave I's disabled sample were not re-interviewed. 
confusability of appearance, the twins are classified as "uncertain zygosity". Using the responses from Wave I questionnaire, those classified as uncertain zygosity were asked in Wave II for cheek samples for DNA analysis. There are 43 twin pairs that refused to provide a sample for testing, and they are deleted from our sample. After deleting twins with undetermined zygosity, the raw sample of siblings (including twins) consists of 4,030 individuals. Of these, 1,986 are full siblings, 700 are half siblings, 821 are DZ twins and 523 are $\mathrm{MZ}$ twins. The sample of twins contains the $\mathrm{DZ}$ and $\mathrm{MZ}$ twins; and the sample of identical twins consists of the $523 \mathrm{MZ}$ twins. Twins constitute 7 percent of the sample. ${ }^{15}$ There is one set of triplets and no quadruplets. The triplets are coded as three sets of twins. The survey includes a number of detailed questions about delinquent behavior of adolescents. Specifically, respondents were asked whether they had committed any of the following acts in the 12 months prior to the interview date: robbery, burglary, damaging property, and theft. Adolescents were also asked about whether they had used different types of illicit drugs such as cocaine, other drugs (heroin, LCD, etc.), inhalants, or ever injected any illegal drugs with a needle. In wave I, the juveniles were asked if they ever used these drugs. In wave II they were asked if they used these drugs since the last interview. Survey administrators took several steps to maintain data security and to minimize the potential for interviewer or parental influence. First, respondents were not provided with any printed questionnaires. Rather, all data were recorded on laptop computers. Second, for sensitive topics, such as delinquent behavior, substance use/abuse, and gun availability, the adolescents

\footnotetext{
${ }^{15}$ The proportion of twins in total births has been rising steadily over the last two decades. When most of the adolescents of the sample were born around 1980, twin births were about 2 percent of total births (National Vital Statistics Report 1999).
} 
listened to pre-recorded questions through earphones and entered their answers directly on the laptops. ${ }^{16}$

Definitions of the variables used in empirical analyses based on the siblings and twins samples and their descriptive statistics are reported in Table $1 .{ }^{17}$ The first two columns of Table 1 report the weighted means and standard deviations of the sibling sample of Wave I. The next column displays the standard deviations of the first-differenced variables, and the last column presents the standard deviations for the first-and-sibling-differenced variables. Some personal and household characteristics, such as race, ethnicity, gender, and whether parents were born in the U.S. do not change between the waves. Therefore, these variables are not reported in Table 1. The deterrence variables in Wave I, such as arrest rates, pertain to 1992, and they were not collected in the second Wave. This is not a drawback because sibling or twin differencing eliminates all variables that are the same across twins or siblings. Put differently, siblings of the same household are exposed to the same time-series variation in contextual variables, such as local economic and social conditions, and deterrence measures. For the analysis of guns-crime relationship, the change in these contextual variables between the two survey years is controlled by state or county dummies.

Table 1 shows that about 24 percent of the 3,394 siblings and twins indicate that guns were available to them at home, and about $22 \%$ of the households in wave I have guns accessible by juveniles. Cook and Ludwig (1996) and Smith (2000) report that in the 1990s 35 to 40 percent of households had firearms. Given that the question posed to the juveniles pertains to "guns available to them," $22 \%$ availability rate appears reasonable. Our data set

\footnotetext{
${ }^{16}$ For less sensitive questions, the interviewer read the questions aloud, and entered the respondent's answers.
} 
also matches well in other dimensions with similar surveys. For example, in our data set, about $10 \%$ of the juveniles responded in the affirmative to the question "have you ever carried a weapon at school?" This response rate is consistent with other youth surveys. In 1993, 8 percent of high school students had carried a gun in the prior 30 days (Kann et al. 1995).

\section{$\underline{\text { V. Results }}$}

\section{Guns and Crime}

In Table 2 we report the estimated coefficients of gun availability at home in four crime regressions using first-differenced data (Equation 3A) on siblings and twins.

Regressions include 21 control variables, including Seatbelt, Height, Weight, GPA, Perceived IQ-Below Average, Perceived IQ-Average, Welfare, Alcohol at Home, Drugs at Home, Allowance, Tattoo, Piercing, No Chance to Live until 35, Good Chance to Live Until 35, Decides Own Curfew on Weekends, Decides Own Curfew on Weeknights, Decides TV Time, Chooses Own Friends, Gut Feeling-Yes, Gut Feeling-Neutral. Regressions also include measures of drug use. Table 2 reports gun coefficients from the models that also include cocaine as a drug use measure. Regressions that included other measures of drug use provided very similar coefficients.

The left-hand-side panel of the table (columns 1-3) reports coefficients unadjusted for measurement error; the right-hand panel (columns 4-6) reports the results with measurement error adjustment (Equation 8). In the second and fifth columns of Table 2 the change in local deterrence and economic conditions between the two years is controlled for by a set of state

\footnotetext{
${ }^{17}$ Questions in Wave II are worded as "Since the last interview ...". Therefore the change in
} 
dummies. The third and sixth columns present the results of the models that include county dummies, under the assumption that time-variation in deterrence and economic conditions where the juvenile resides has an impact on his/her behavior.

The coefficient of gun availability is always significant in robbery, burglary and theft. The magnitudes indicate that having guns available at home increases the probability of robbery, burglary and theft by 1.5 to 2 percentage points after adjusting for the measurement error. If current criminal activity of the juvenile depends positively on his past criminal behavior, and if current gun availability at home is negatively correlated with juvenile's past criminal behavior, the results may be biased downwards. ${ }^{18}$ In that case, the results reported in Table 2 are underestimates of the true impact of gun availability. It is interesting to note that gun availability at home has no impact on the propensity to damage property. To the extent that no gun is needed to damage property, this result is meaningful. ${ }^{19}$

It should be noted that the models include four parental supervision variables (Decides TV time, Decides Own Curfew on Weekends, Decides Own Curfew on Weeknights, and Chooses Own Friends) as well as a variable that measures whether alcohol is available to the juvenile at home, and another variable that measures whether drugs are available at home. Thus, controlling for these family environment and supervision effects, gun availability has a separate, positive impact on delinquent behavior. We also estimated

behavior between the two waves is easily identifiable.

${ }^{18}$ Specifically, if an increase in criminal behavior between time periods $\mathrm{t}-2$ and $\mathrm{t}-1\left(\Delta \mathrm{CR}_{\mathrm{t}-1}\right)$ motivates parents to eliminate guns at home $\left(\Delta \mathrm{G}_{\mathrm{t}}<0\right)$, and if $\left(\Delta \mathrm{CR}_{\mathrm{t}-1}\right)$ is positively correlated with the dependent variable $\Delta \mathrm{CR}_{\mathrm{t}}$, the estimated impact of guns will be biased down. We thank John Donohue for this insight.

19 The point estimate is similar to the ones estimated in burglary, robbery and theft equations. The explanatory variable is same (the change in access to guns) in all regressions, and the change in damaging property exhibits more variation than other crime categories (see Table 1). 
the same models using first-differenced data on all juveniles $(n=11,456)$. Neither the magnitudes nor the statistical significance of the results changed.

If availability of guns at home is interpreted as a sign of undesirable home environment, and if such an environment impacts the juvenile's criminal behavior, then the relationship between guns and crime is not causal, but it is a reflection of the influence of harmful home environment. For example, if most parents who allow their children to have access to guns at home have criminal tendencies themselves, and if such criminal human capital is transmitted to the child, then having access to guns is a proxy for a tendency for criminal behavior. We have no information on the criminal records of the parents, but it should be emphasized that taking first-differences of the data eliminates parent-specific as well as child-specific heterogeneity, such as unobserved tendency for criminal delinquency.

Nevertheless, to test whether gun availability at home is merely a measure of unobserved time-varying parent characteristics that also impact child behavior, we investigated if the change in gun availability has an impact on the change in other ill-behavior of the child such as lying, being expelled from school, drinking and fighting, smoking, and having sex. ${ }^{20}$

If having guns available at home is a proxy of the home environment, then it should have an impact on these behaviors as well. The results, reported in Table 3, demonstrate that availability of guns at home has no impact on lying, being expelled from school, smoking, drinking \& fighting, and having sex. The point estimates are small, negative in half of the

\footnotetext{
${ }^{20}$ In Wave I the questions for these behaviors are: "Have you ever lied to your parents or guardians about where you have been or whom you were with?," Have you ever being expelled from school?," "Have you ever tried cigarette smoking?," "Did you get into a physical fight because you had been drinking in the last 12 months?," and "Have you ever had sexual intercourse?" In Wave II, the same questions were asked as "Since the last interview, have you ...".
} 
cases, and never statistically significant. This indicates that having guns available at home is positively related to criminal activity, but it has no significant impact on other types of bad behavior.

One main argument in favor of concealed weapons laws is that they allow lawabiding citizens to protect themselves from potential perpetrators. As a result, carrying a firearm is expected to decrease criminal victimization. We provide a test of this hypothesis. The data set contains four questions that measure criminal victimization of the juvenile. They are "whether during the past 12 months someone pulled a knife or gun on you," "whether during the past 12 months someone shot you," "whether during the past 12 months someone cut you or stabbed you," and "whether during the past 12 months you were jumped." Using the same set of explanatory variables, we estimated the probability of victimization based on these questions. The results, which are reported in Table 4 reveal that having access to guns does not decrease the probability of victimization for juveniles. In fact, gun availability increases the probability of being cut or stabbed, and the probability of someone pulling a knife or gun on the juvenile by about 2 percentage points. The increase in the probability of victimization can be because juveniles may become overconfident because of guns being available to them. As a result, they may engage in situations with less certain outcomes. This point has been demonstrated theoretically by Donohue III and Levitt (1998). The upshot is that, the results show that gun availability has a positive impact on juvenile crime, and it also increases the risk of being victimized. 


\section{Drugs and Crime}

In Table 5 we report the estimated coefficients of drug use indicators using the sample of siblings (including twins). The top panel presents results pertaining to Equation (3A), which is the fixed-effects model. As in Table 2, in addition to drug use measures, the regressions include the following explanatory variables: Seatbelt, Height, Weight, GPA, Perceived IQ-Below Average, Perceived IQ-Average, Welfare, Alcohol at Home, Drugs at Home, Guns at Home, Allowance, Tattoo, Piercing, No Chance to Live until 35, Good Chance to Live Until 35, Decides Own Curfew on Weekends, Decides Own Curfew on Weeknights, Decides TV Time, Chooses Own Friends, Gut Feeling-Yes, Gut FeelingNeutral.

The bottom panel of Table 5 displays the results obtained from Equation (4), which involves time-differencing as well as sibling-differencing. In this specification variables pertaining to family attributes drop out as they do not vary between siblings. Both panels of Table 5 display two sets of results. The left-hand-side presents the results unadjusted for measurement error in drug use, where the right-hand-side displays the results with measurement error adjustment. For each drug variable we used specific values of $\Phi$ obtained from the data.

As Table 5 demonstrates, drug use coefficients are positive and significantly different from zero in almost all cases in the top panel, and a similar picture emerges in the bottom panel, with the exception of the impact of Other Drugs. ${ }^{21}$

\footnotetext{
${ }^{21}$ Note that the relative sample size of the first-differenced and first-and-sibling differenced data depends on the number of siblings in households. For example, if a household consists of two siblings, the first differenced (time-differenced) data will contain two observations, and the first-andsibling differenced data will contain one observation. On the other hand, if the household consists of three siblings $\mathrm{A}, \mathrm{B}$ and $\mathrm{C}$, the first-differenced data will contain three observations, and the first-and-
} 
Table 6 presents the results for twins. As in Table 5, the upper panel displays the results of the fixed-effects model (Equation 3A), while the lower panel contains the results obtained from time- and within-twin differencing. ${ }^{22}$ To the extent that individual unobserved time-varying heterogeneity is the same between twins, this specification is represented by Equation (5). Although the sample size goes down to about 450 in case of twins, drug use coefficients remain significant in many cases, even in models with time and twindifferencing. For example, in the lower panel cocaine consumption impacts theft and damage. Other drugs influence burglary, theft, and damage. Injection is associated with an increase in the propensity to commit burglary and theft.

Table 7 displays the results for identical twins. Although there are only 400 observations in the fixed-effects model (top panel), with the exception of theft, each crime is influenced by two different drug measures. For example, robberies are influenced by using cocaine and inhalants, burglaries are influenced by inhalants and injection, and damage is influenced by using inhalants and other drugs. In the lower panel where the results of fixedeffects and within twin differences are reported, the sample size goes down to 176, and therefore, the coefficients are not estimated with precision. Nevertheless, injection is statistically significant in burglary and theft equations, and other drugs is significant in the damage regression.

The results in Tables 5-7 demonstrate the positive impact of drug use on crime. Although the precision of the estimated coefficients goes down as the sample gets smaller,

sibling differenced data will also contain three observations (it will consist of $\Delta \mathrm{A}-\Delta \mathrm{B}, \Delta \mathrm{A}-\Delta \mathrm{C}$ and $\Delta \mathrm{B}-\Delta \mathrm{C}$, where $\Delta \mathrm{A}$ is a first-differenced variable of sibling $\mathrm{A}$ ). In case of a household with four siblings, the first-differenced data have four observations and first-and-sibling differenced data have six observations. 
the point estimates of individual drug variables are stable across specifications. We calculated the median point estimate for each drug category across crime types. In models with first-differences the median impact on crime of using cocaine is 11 percentage points. The impact of using inhalants is 14 percentage points. The median impacts on crime of other drugs and injecting drugs are 5 and 27 percentage points, respectively. In double-differenced models the median impacts are 14 percentage points for inhalants, 18 percentage points for other drugs, 23 percentage points for cocaine, and 50 percentage points for injection. The results for injection should be taken with caution because of the small number of users in this case.

\section{Reverse causality}

Although taking first and sibling (or twin) differences eliminates unobserved heterogeneity that would otherwise have been included in the error terms, it can still be argued that drug use may be influenced by reverse causality from property crimes if committing these crimes is associated with increased income. To account for this potential reverse causality, we considered a reduced-form drug use equation, where the instruments that impact the drug use of the juvenile include the following variables: whether at least one of the three best friends smokes at least one cigarette a day, whether at least one of the three best friends drinks alcohol at least once a month, and whether at least one of the three best friends uses marijuana at least once a month. While it can plausibly be argued that friends' consumption of cigarette, alcohol and marijuana may be correlated with own drug use, it is less obvious that these instruments are uncorrelated with own criminal activity.

\footnotetext{
${ }^{22}$ The sample size of the first-and-twin differenced data is not half of the first-differenced twin sample
} 
Unfortunately no better instruments are available. State or county level alcohol and drug prices are not viable candidates to identify the effect of drug use as they do not vary between siblings and twins. School based policy variables are not useful either, because all twins and most siblings attend the same school. ${ }^{23}$ Estimation of the double-differenced crime and double-differenced reduced-form drug use equations with full-information maximum likelihood revealed that although the magnitudes of the estimated drug use coefficients are similar to those reported in tables 5-7, most coefficients are not estimated with precision. The imprecision of the estimated coefficients is most likely due to weak instruments, but the data set does not include better instrument candidates. (The explicit specification is reported in Appendix B).

In Table A-1 in Appendix B we report the coefficients for inhale and inject for siblings, twins and identical twins. These are the drugs that created most precise estimates. For siblings, the use of inhalants has a positive impact on burglary, theft, and damage. Injection has an impact on robbery and burglary. In case of all twins, injection has an impact on theft, and in the sample of identical twins injection influences burglary and theft.

\section{$\underline{\text { VI. Conclusion }}$}

The analysis of the determinants of juvenile risky behavior in general, and juvenile crime in particular has become an important research question (Gruber 2001, Levitt 1998b, Mocan and Rees 1999). In addition to sanctions, economic variables and social factors, guns and drug use are potentially important determinants of criminal activity. The causal effect of

because of missing values in some variables.

${ }^{23}$ Grossman, Kaestner and Markowitz (2002) highlight the same point in their analysis of drug use on teenage sexual activity. 
drug use on crime has not yet been established due to statistical difficulties. The propensity to use drugs may be correlated with unobserved attributes and characteristics of the individual. If these attributes, such as risk aversion or intelligence, have an influence on criminal activity, then estimates of drug use on crime are biased because of this confounding. The same difficulty exists in research on guns-crime relationship, which used aggregate (state or county-level) data. In addition, it has been difficult to find data sets with measures of gun availability. Therefore, researchers explained crime rates with some proxies of gun ownership, such as sales of gun magazines, or suicides involving firearms. Alternatively, they analyzed the impact of gun laws on state or county crime rates.

In this paper we employ the AddHealth data, which is a nationally-representative panel data set of high school students that contains an oversample of siblings and twins. In addition to an unusually large number of interesting variables that aim to gauge personal characteristics, family background and family supervision, the data set includes a direct question on the availability of guns to the juvenile at home. The data set also contains detailed information about drug use and criminal activity of the juveniles. In particular, consumption of cocaine, injecting drugs, using inhalants, and using other drugs are measured. The crimes we analyze are robberies, burglaries and thefts committed by juveniles and whether they damaged property.

We adjust for measurement error in gun availability and drug use with an algorithm that allows for non-symmetric measurement error. The impact of gun availability on crime is analyzed using first-differenced data, where time-invariant individual-specific and familyspecific heterogeneity is eliminated. 
The results reveal that gun availability at home increases the propensity to commit robbery, burglary and theft by two percentage points for juveniles, but it has no impact on damaging property. It is unlikely that gun availability is merely a measure of the unobserved home environment. This is because other measures of home environment, such as various parent supervision variables and variables that indicate the availability of alcohol and the availability of drugs at home, have no similar systematic impacts on crime. More important, gun availability at home has no impact on other bad behavior, such as lying, being expelled from school, drinking and fighting, smoking and having sex.

We also investigate whether gun availability decreases the probability of being a crime victim. We find no support for this hypothesis; in fact the results show that having access to guns increases the probability of being cut or stabbed by someone and someone pulling a knife or gun on the juvenile.

The variation of drug use between siblings and twins allows us to exploit withinsibling differences of the first-differenced data. This enables us to filter out time-varying unobservables that are common to each household (therefore to each sibling). In addition, taking the twin differences of the first-differenced data enables us to eliminate the genetic component of criminal activity common to both twins.

The results indicate that drug use increases the propensity to commit crime. The median impact of injecting drugs on the probability of committing robbery, burglary and theft and creating property damage is 50 percentage points, although this result should be taken with caution because it is based on small number of individuals who inject drugs. The median impact of cocaine is an increased criminal propensity of 23 percentage points. The use of inhalants generates a (median) 14 percentage point increase in the propensity to 
commit crime; and other drugs increase the propensity to commit crime by 18 percentage points.

Given the impact of juvenile criminal activity on human capital accumulation and future earnings, and given the magnitude of the externalities generated by juvenile crime cited in the introduction, these results suggest that the current debates on gun control and drug policies have dimensions in addition to individual liberties and constitutional rights. 


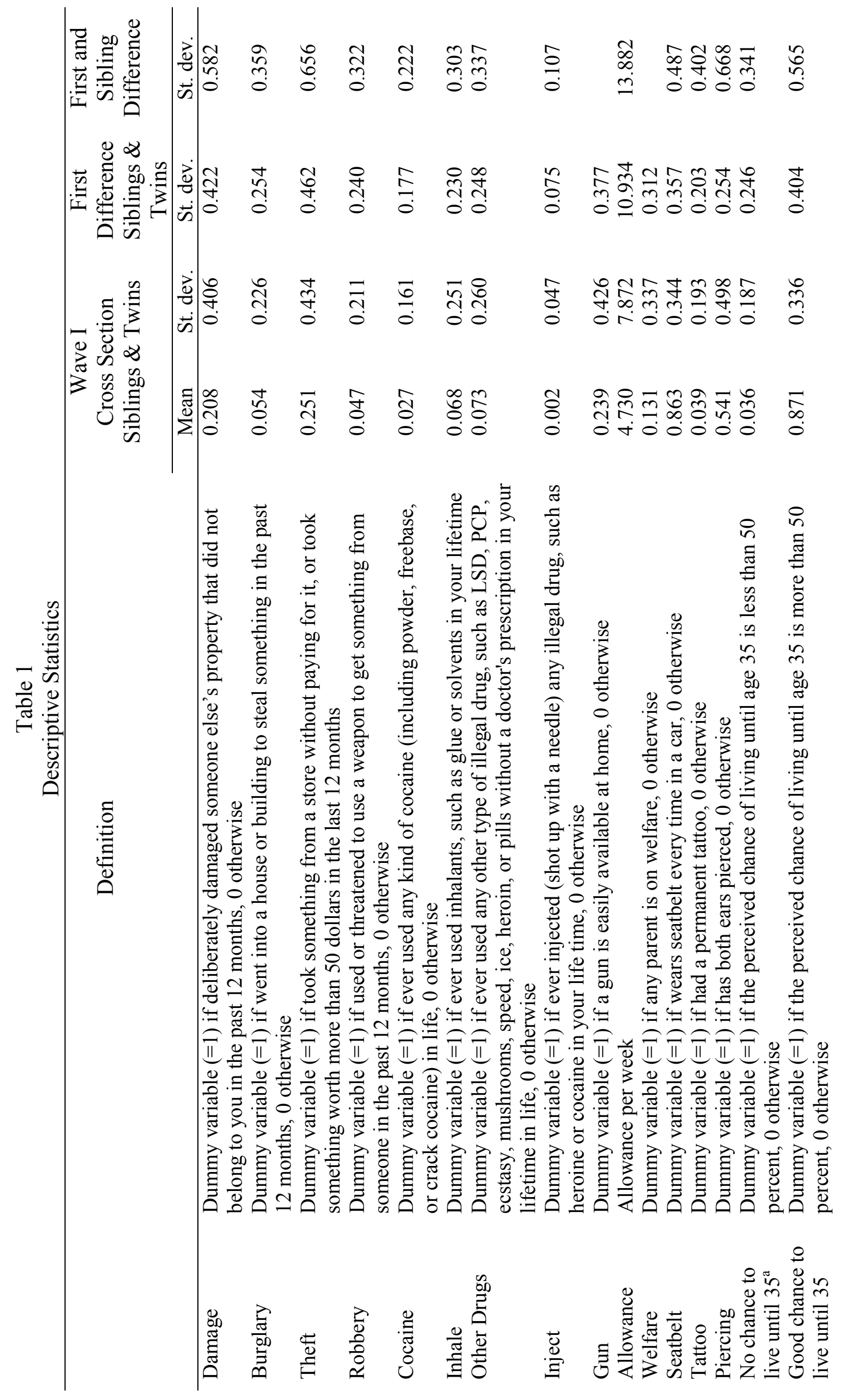




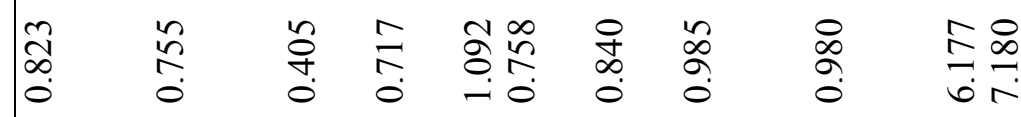

童

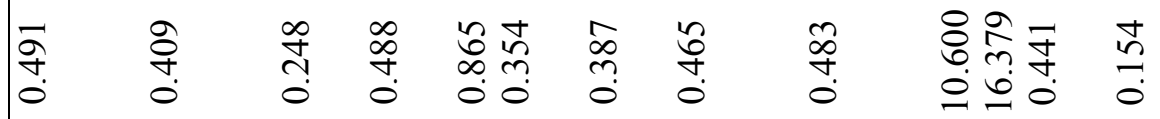

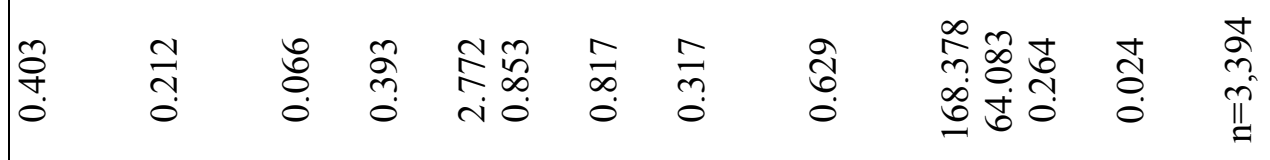

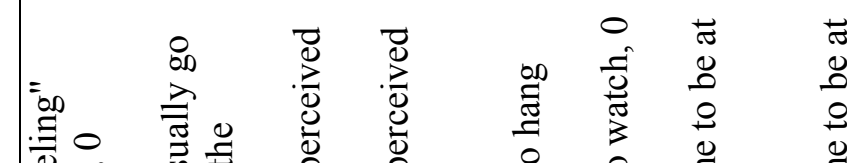

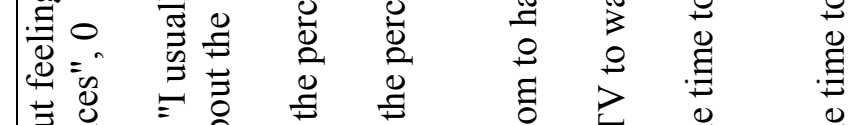

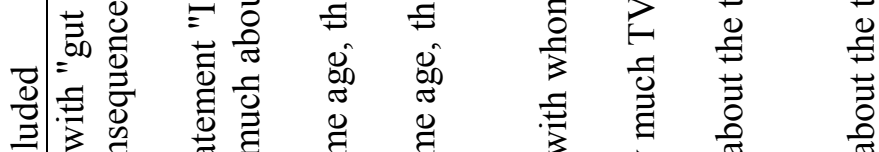

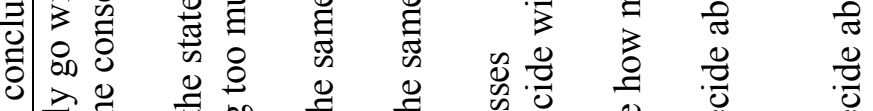

可焉

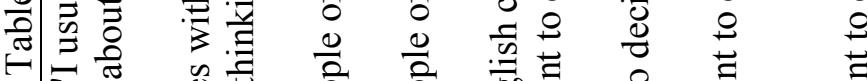

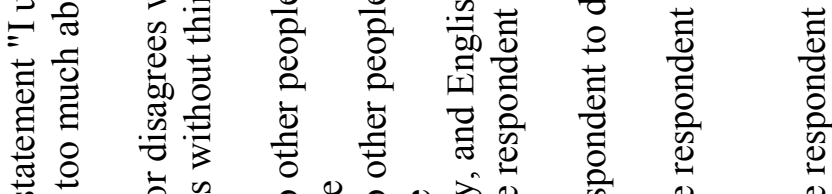

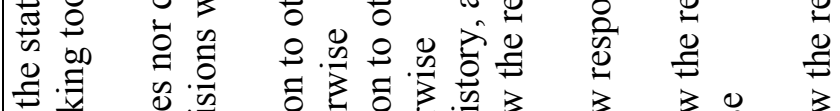

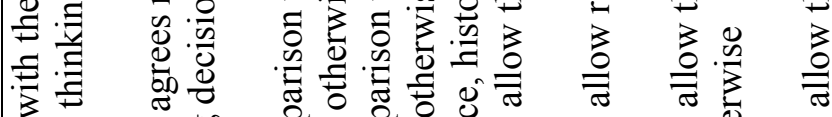

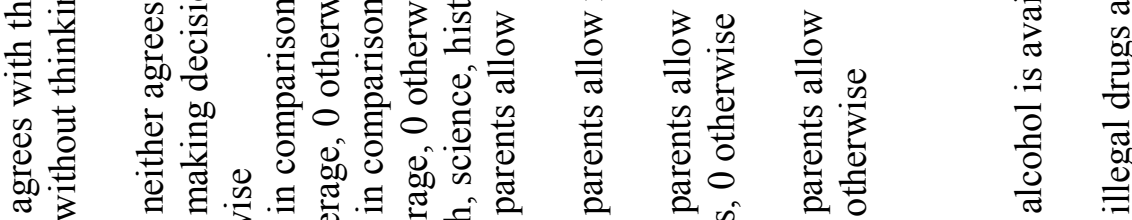

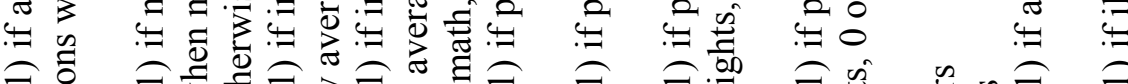

II $\frac{0}{\pi}$ 开

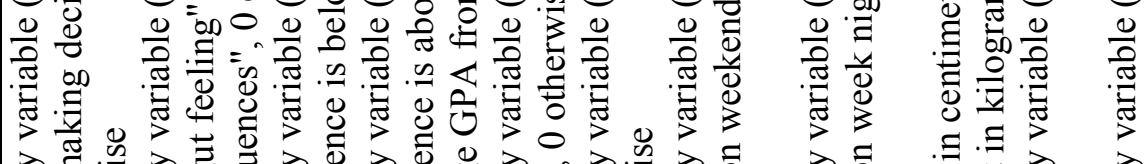

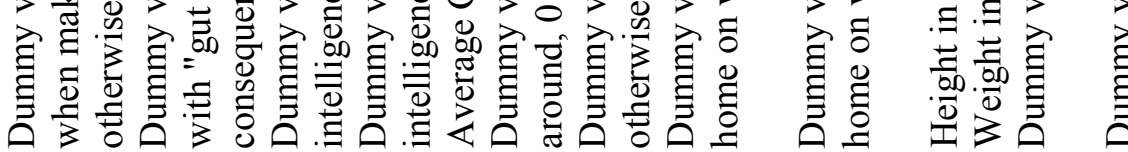

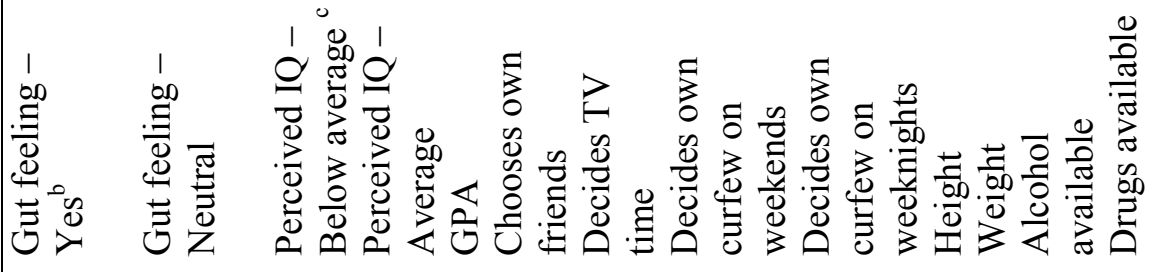


Table 2

The Impact of Gun Availability at Home on Crime

All Siblings (Including Twins)

First Differenced Data

Coefficient of Gun Availability

\begin{tabular}{lccc|ccc}
\hline & \multicolumn{2}{c}{ w/o Measurement Error Correction } & \multicolumn{3}{c}{ W/ Measurement Error Correction } \\
\hline & $(1)$ & $(2)$ & $(3)$ & $(4)$ & $(5)$ & $(6)$ \\
\hline Damage & 0.034 & 0.038 & 0.038 & 0.016 & 0.018 & 0.018 \\
& $(0.023)$ & $(0.023)$ & $(0.024)$ & $(0.011)$ & $(0.011)$ & $(0.012)$ \\
Burglary & $0.031^{* *}$ & $0.030^{* *}$ & $0.030^{* *}$ & $0.015^{* *}$ & $0.015^{* *}$ & $0.015^{* *}$ \\
& $(0.013)$ & $(0.013)$ & $(0.013)$ & $(0.006)$ & $(0.006)$ & $(0.006)$ \\
Robbery & $0.028^{* *}$ & $0.025^{* *}$ & $0.022^{*}$ & $0.014^{* *}$ & $0.012^{* *}$ & $0.011^{*}$ \\
& $(0.012)$ & $(0.012)$ & $(0.013)$ & $(0.006)$ & $(0.006)$ & $(0.006)$ \\
& $0.039^{*}$ & $0.045^{* *}$ & $0.042^{*}$ & $0.019^{*}$ & $0.022^{* *}$ & $0.020^{*}$ \\
Theft & $(0.022)$ & $(0.023)$ & $(0.024)$ & $(0.011)$ & $(0.011)$ & $(0.012)$ \\
& No & Yes & No & No & Yes & No \\
State Dummies & No & No & Yes & No & No & Yes \\
County Dummies & No & &
\end{tabular}

The entries are the coefficients of gun availability at home. Robust standard errors are in parentheses.

Table 3

The Impact of Gun Availability on Other Behavior

All Siblings (Including Twins)

First Differenced Data

\begin{tabular}{|c|c|c|c|c|c|c|}
\hline & \multicolumn{6}{|c|}{ Coefficient of Gun Availability } \\
\hline & \multicolumn{3}{|c|}{ w/o Measurement Error Correction } & \multicolumn{3}{|c|}{ w/ Measurement Error Correction } \\
\hline & $(1)$ & $(2)$ & (3) & $(4)$ & $(5)$ & $(6)$ \\
\hline Smoking & $\begin{array}{l}-0.027 \\
(0.023)\end{array}$ & $\begin{array}{l}-0.021 \\
(0.023)\end{array}$ & $\begin{array}{l}-0.008 \\
(0.023)\end{array}$ & $\begin{array}{l}-0.013 \\
(0.011)\end{array}$ & $\begin{array}{l}-0.010 \\
(0.011)\end{array}$ & $\begin{array}{l}-0.004 \\
(0.011)\end{array}$ \\
\hline $\begin{array}{l}\text { Drinking \& } \\
\text { Fighting }\end{array}$ & $\begin{array}{c}0.003 \\
(0.015)\end{array}$ & $\begin{array}{l}-0.002 \\
(0.015)\end{array}$ & $\begin{array}{l}-0.001 \\
(0.015)\end{array}$ & $\begin{array}{c}0.001 \\
(0.007)\end{array}$ & $\begin{array}{c}-0.001 \\
(0.007)\end{array}$ & $\begin{array}{l}-0.0005 \\
(0.0073\end{array}$ \\
\hline Lying & $\begin{array}{c}0.040 \\
(0.029)\end{array}$ & $\begin{array}{c}0.038 \\
(0.030)\end{array}$ & $\begin{array}{c}0.041 \\
(0.030)\end{array}$ & $\begin{array}{c}0.019 \\
(0.014)\end{array}$ & $\begin{array}{c}0.018 \\
(0.015)\end{array}$ & $\begin{array}{c}0.020 \\
(0.015)\end{array}$ \\
\hline $\begin{array}{l}\text { Being Expelled } \\
\text { From School }\end{array}$ & $\begin{array}{c}0.000 \\
(0.010)\end{array}$ & $\begin{array}{c}-0.001 \\
(0.010)\end{array}$ & $\begin{array}{l}-0.002 \\
(0.010)\end{array}$ & $\begin{array}{c}0.000 \\
(0.005)\end{array}$ & $\begin{array}{l}-0.0005 \\
(0.0048)\end{array}$ & $\begin{array}{l}-0.001 \\
(0.005)\end{array}$ \\
\hline Having Sex & $\begin{array}{l}-0.001 \\
(0.021)\end{array}$ & $\begin{array}{c}0.003 \\
(0.021)\end{array}$ & $\begin{array}{c}0.004 \\
(0.022)\end{array}$ & $\begin{array}{c}0.0005 \\
(0.0102)\end{array}$ & $\begin{array}{c}0.001 \\
(0.010)\end{array}$ & $\begin{array}{c}0.002 \\
(0.011)\end{array}$ \\
\hline $\begin{array}{l}\text { State Dummies } \\
\text { County Dummies }\end{array}$ & $\begin{array}{l}\text { No } \\
\text { No }\end{array}$ & $\begin{array}{l}\text { Yes } \\
\text { No }\end{array}$ & $\begin{array}{l}\text { No } \\
\text { Yes }\end{array}$ & $\begin{array}{l}\text { No } \\
\text { No }\end{array}$ & $\begin{array}{l}\text { Yes } \\
\text { No }\end{array}$ & $\begin{array}{l}\text { No } \\
\text { Yes }\end{array}$ \\
\hline
\end{tabular}

The entries are the coefficients of gun availability at home. Robust standard errors are in parentheses. 
Table 4

The Impact of Gun Availability on Victimization

All Siblings (Including Twins)

First Differenced Data

\begin{tabular}{cccc|ccc}
\hline \multicolumn{7}{c}{ Coefficient of Gun Availability } \\
\hline & \multicolumn{7}{c}{ w/o Measurement Error Correction } & \multicolumn{2}{c}{ w/ Measurement Error Correction } \\
\hline Someone pulled a & $(1)$ & $(2)$ & $(3)$ & $(4)$ & $(5)$ & $(6)$ \\
knife or gun on you & $0.048^{* * *}$ & $0.048^{* *}$ & $0.045^{* *}$ & $0.023^{* * *}$ & $0.023^{* *}$ & $0.022^{* *}$ \\
& $(0.018)$ & $(0.019)$ & $(0.019)$ & $(0.009)$ & $(0.009)$ & $(0.009)$ \\
Someone shot you & 0.003 & 0.004 & 0.003 & 0.001 & 0.002 & 0.001 \\
& $(0.008)$ & $(0.008)$ & $(0.009)$ & $(0.004)$ & $(0.004)$ & $(0.004)$ \\
Someone cut you or & $0.046^{* * *}$ & $0.043^{* * *}$ & $0.044^{* * *}$ & $0.022^{* * *}$ & $0.021^{* * *}$ & $0.021^{* * *}$ \\
stubbed you & $(0.014)$ & $(0.014)$ & $(0.014)$ & $(0.007)$ & $(0.007)$ & $(0.007)$ \\
& -0.001 & -0.001 & 0.001 & -0.0005 & -0.0005 & 0.0005 \\
You were & $(0.001)$ & $(0.015)$ & $(0.016)$ & $(0.0005)$ & $(0.0073)$ & $(0.0077)$ \\
jumped & & & & & & No \\
State Dummies & No & Yes & No & No & Yes & No \\
County Dummies & No & No & Yes & No & No & Yes \\
\hline
\end{tabular}

The entries are the coefficients of gun availability at home. Robust standard errors are in parentheses. 
Table 5

The Impact of Drug Use on Crime

All Siblings (Including Twins)

First-Differenced Data

w/o Measurement Error Correction

w/ Measurement Error Correction

\begin{tabular}{|c|c|c|c|c|c|c|c|c|}
\hline & Robbery & Burglary & Theft & Damage & Robbery & Burglary & Theft & Damage \\
\hline Cocaine & $\begin{array}{c}0.145^{* * *} * \\
(0.047)\end{array}$ & $\begin{array}{c}0.136 * * * \\
(0.04)\end{array}$ & $\begin{array}{c}0.137 * * * \\
(0.053)\end{array}$ & $\begin{array}{c}0.158 * * * \\
(0.053)\end{array}$ & $\begin{array}{c}0.115 * * * \\
(0.037)\end{array}$ & $\begin{array}{c}0.108 * * * \\
(0.032)\end{array}$ & $\begin{array}{c}0.109 * * * \\
(0.042)\end{array}$ & $\begin{array}{c}0.125 * * * \\
(0.042)\end{array}$ \\
\hline Inhale & $\begin{array}{c}0.165 * * * \\
(0.035)\end{array}$ & $\begin{array}{c}0.156 * * * \\
(0.033)\end{array}$ & $\begin{array}{c}0.19 * * * \\
(0.043)\end{array}$ & $\begin{array}{c}0.177 * * * \\
(0.041)\end{array}$ & $\begin{array}{c}0.131 * * * \\
(0.028)\end{array}$ & $\begin{array}{c}0.124 * * * \\
(0.026)\end{array}$ & $\begin{array}{c}0.151 * * * \\
(0.034)\end{array}$ & $\begin{array}{c}0.14 * * * \\
(0.033)\end{array}$ \\
\hline Other Drugs & $\begin{array}{c}0.033 \\
(0.031)\end{array}$ & $\begin{array}{c}0.052 * \\
(0.029)\end{array}$ & $\begin{array}{c}0.08 * * \\
(0.04)\end{array}$ & $\begin{array}{c}0.123 * * * \\
(0.041)\end{array}$ & $\begin{array}{l}0.021 \\
(0.02)\end{array}$ & $\begin{array}{c}0.033^{*} \\
(0.019)\end{array}$ & $\begin{array}{c}0.051 * * \\
(0.026)\end{array}$ & $\begin{array}{c}0.079 * * \\
(0.026)\end{array}$ \\
\hline Inject & $\begin{array}{c}0.193 \\
(0.158)\end{array}$ & $\begin{array}{c}0.328 * * * \\
(0.112)\end{array}$ & $\begin{array}{c}0.472 * * * \\
(0.11)\end{array}$ & $\begin{array}{c}0.295^{*} \\
(0.159)\end{array}$ & $\begin{array}{c}0.17 \\
(0.139)\end{array}$ & $\begin{array}{c}0.29 * * * \\
(0.099)\end{array}$ & $\begin{array}{c}0.417 * * * \\
(0.097)\end{array}$ & $\begin{array}{l}0.26^{*} \\
(0.14)\end{array}$ \\
\hline
\end{tabular}

First- and - Sibling Differenced Data

w/o Measurement Error Correction

w/ Measurement Error Correction

Robbery Burglary Theft Damage Robbery Burglary Theft Damage

Cocaine

$0.142 * * \quad 0.155 * * * \quad 0.154 *$

0.118

$0.098 * *$

$0.107 * * *$

$0.107 *$

0.082

$(0.062)$

(0.086)

$(0.086)$

$(0.043)$

(0.04)

(0.06)

(0.06)

Inhale

$0.128 * * * \quad 0.168 * * * \quad 0.21 * * *$

$0.155 * *$

$0.094 * * *$

$0.124 * * *$

$0.155 * * * \quad 0.114 * *$

$(0.041) \quad(0.043)$

$(0.065)$

$(0.063) \quad(0.03)$

$(0.032)$

(0.048)

(0.046)

Other Drugs

\begin{tabular}{cccc|cccc}
0.004 & 0.066 & 0.065 & 0.093 & 0.002 & 0.04 & 0.039 & 0.056 \\
$(0.039)$ & $(0.042)$ & $(0.062)$ & $(0.059)$ & $(0.024)$ & $(0.026)$ & $(0.038)$ & $(0.036)$
\end{tabular}

Inject

$$
0.403 * * \quad 0.511 * * * \quad 0.754 * * * \quad 0.404 * *
$$

$\begin{array}{llll}0.357 * * & 0.453 * * * & 0.669 * * * & 0.358 * *\end{array}$ $(0.159)$ $(0.151)$ (0.135) $(0.163)$ $(0.141) \quad(0.134)$ (0.12) $(0.145)$

$*$, **, and $* * *$ indicate statistical significance at $<10 \%,<5 \%$, and $<1 \%$ levels, respectively.

Robust standard errors are in parentheses.

In the upper panel of the table, sample sizes range from 3,049 to 3,055 for robbery, from 3,048 to 3,054 for burglary, from 3,046 to 3,052 for theft, and from 3,050 to 3.056 for damage. In the lower panel, sample sizes range from 1,304 to 1,307 for robbery, from 1,300 to 1,303 for burglary, from 1,304 to 1,307 for theft, and from 1,303 to 1,306 for damage. 
Table 6

The Impact of Drug Use on Crime

All Twins

\begin{tabular}{|c|c|c|c|c|c|c|c|c|}
\hline & & & First- & ifferenced & Data & & & \\
\hline & w/o N & leasuremen & it Error Cor & ction & $\mathrm{w} / \mathrm{M}$ & easuremen & Error Corr & ction \\
\hline & Robbery & Burglary & Theft & Damage & Robbery & Burglary & Theft & Damage \\
\hline Cocaine & $\begin{array}{l}0.165 * \\
(0.096)\end{array}$ & $\begin{array}{l}0.116 * \\
(0.062)\end{array}$ & $\begin{array}{c}0.116 \\
(0.095)\end{array}$ & $\begin{array}{l}0.153 * \\
(0.081)\end{array}$ & $\begin{array}{l}0.125 * \\
(0.073)\end{array}$ & $\begin{array}{c}0.088 * \\
(0.047)\end{array}$ & $\begin{array}{c}0.088 \\
(0.072)\end{array}$ & $\begin{array}{l}0.116^{*} \\
(0.061)\end{array}$ \\
\hline Inhale & $\begin{array}{c}0.216^{* * *} \\
(0.068)\end{array}$ & $\begin{array}{c}0.156^{* * *} \\
(0.054)\end{array}$ & $\begin{array}{c}0.175 * * \\
(0.087)\end{array}$ & $\begin{array}{c}0.22 * * * \\
(0.07)\end{array}$ & $\begin{array}{c}0.168 * * * \\
(0.053)\end{array}$ & $\begin{array}{c}0.121 * * * \\
(0.042)\end{array}$ & $\begin{array}{c}0.136 * * \\
(0.067)\end{array}$ & $\begin{array}{c}0.171 * * * \\
(-0.054)\end{array}$ \\
\hline Other Drugs & $\begin{array}{c}0.112 * * \\
(0.055)\end{array}$ & $\begin{array}{c}0.054 \\
(0.043)\end{array}$ & $\begin{array}{c}0.088 \\
(0.066)\end{array}$ & $\begin{array}{c}0.154 * * \\
(0.068)\end{array}$ & $\begin{array}{c}0.067 * * \\
(0.033)\end{array}$ & $\begin{array}{c}0.032 \\
(0.026)\end{array}$ & $\begin{array}{c}0.052 \\
(0.039)\end{array}$ & $\begin{array}{c}0.092 * * \\
(0.041)\end{array}$ \\
\hline Inject & $\begin{array}{c}-0.297 \\
(0.307)\end{array}$ & $\begin{array}{c}0.325 \\
(0.199)\end{array}$ & $\begin{array}{c}0.249 \\
(0.198)\end{array}$ & $\begin{array}{c}0.195 \\
(0.335)\end{array}$ & $\begin{array}{c}-0.298 \\
(0.308)\end{array}$ & $\begin{array}{c}0.326 \\
(0.2)\end{array}$ & $\begin{array}{c}0.25 \\
(0.199)\end{array}$ & $\begin{array}{c}0.196 \\
(0.336)\end{array}$ \\
\hline
\end{tabular}

First-and-Twin Differenced Data

w/o Measurement Error Correction w/ Measurement Error Correction

\begin{tabular}{lcccc|cccc} 
& Robbery & Burglary & Theft & Damage & Robbery & Burglary & Theft & Damage \\
\hline \multirow{2}{*}{ Cocaine } & 0.183 & 0.088 & $0.268^{* *}$ & $0.278^{*}$ & 0.119 & 0.057 & $0.175^{* *}$ & $0.181^{*}$ \\
& $(0.111)$ & $(0.109)$ & $(0.128)$ & $(0.149)$ & $(0.072)$ & $(0.071)$ & $(0.084)$ & $(0.097)$ \\
\multirow{2}{*}{ Inhale } & 0.078 & 0.118 & 0.168 & 0.081 & 0.058 & 0.087 & 0.124 & 0.06 \\
& $(0.079)$ & $(0.086)$ & $(0.124)$ & $(0.097)$ & $(0.058)$ & $(0.064)$ & $(0.092)$ & $(0.072)$ \\
Other Drugs & 0.082 & $0.121 *$ & $0.174 *$ & $0.258 * *$ & 0.049 & $0.073 *$ & $0.105 *$ & $0.155^{* * *}$ \\
& $(0.068)$ & $(0.063)$ & $(0.098)$ & $(0.09)$ & $(0.041)$ & $(0.038)$ & $(0.059)$ & $(0.054)$ \\
Inject & & & & & & & & \\
& -0.105 & $0.67 *$ & $0.964 * * *$ & 0.097 & -0.105 & $0.669 *$ & $0.962 * * *$ & 0.097 \\
& $(0.295)$ & $(0.363)$ & $(0.365)$ & $(0.204)$ & $(0.294)$ & $(0.362)$ & $(0.364)$ & $(0.204)$ \\
\hline
\end{tabular}

$*, * *$, and $* * *$ indicate statistical significance at $<10 \%,<5 \%$, and $<1 \%$ levels, respectively.

Robust standard errors are in parentheses.

In the upper panel of the table, sample sizes range from 1,040 to 1,041 for robbery and burglary,

from 1,039 to 1,040 for theft, and from 1,041 to 1,042 for damage. In the lower panel, sample sizes

range from 452 to 453 for robbery and burglary, from 453 to 454 for theft and damage. 
Table 7

The Impact of Drug Use on Crime

Identical Twins

First-Differenced Data

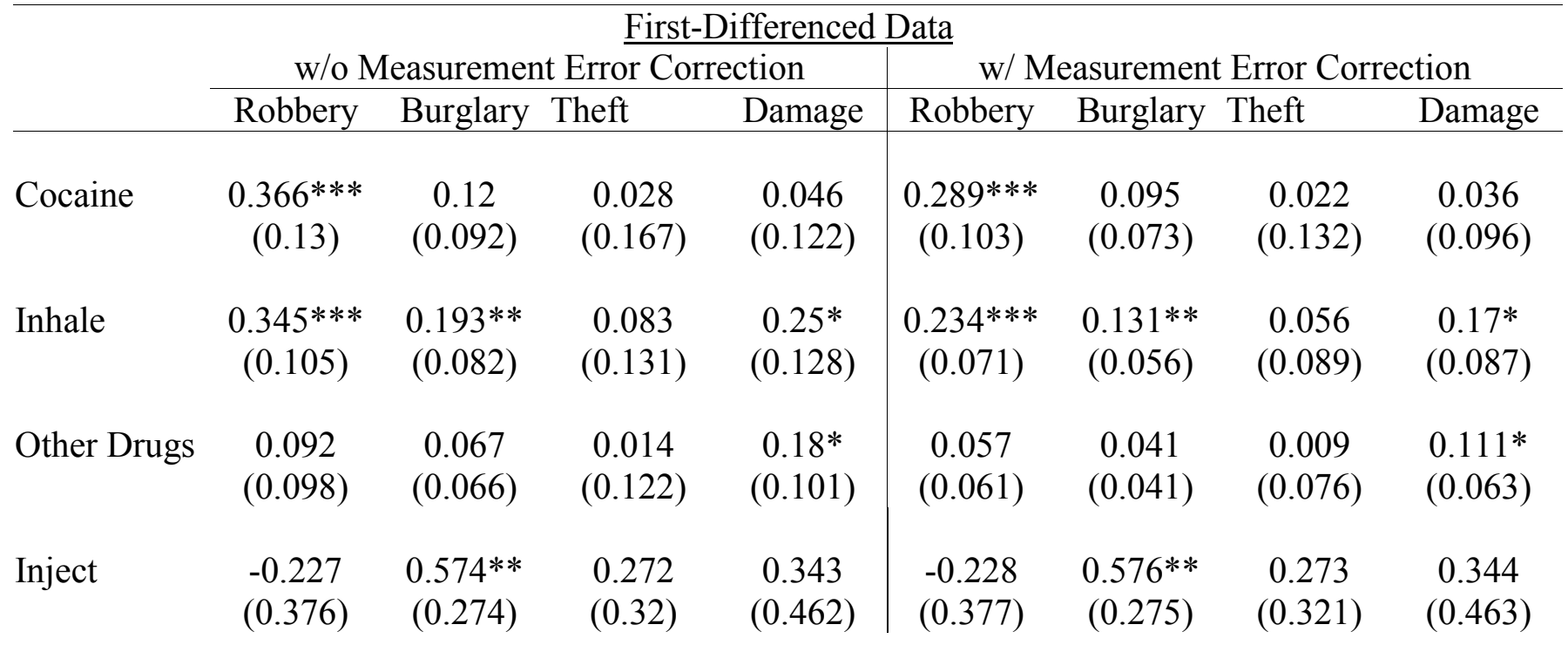

First-and-Twin Differenced Data

w/o Measurement Error Correction Robbery Burglary Theft

Cocaine

$0.219 \quad 0$

$(0.149) \quad(0.23)$

0.219

(0.144)

$-0.195$

(0.149)

0.16
$(0.109)$

$(0.168)$

0.16

(0.105) Robbery

Burglary Theft

ction

Inhale

$0.043 \quad 0.08$

(0.113)

(0.183)

$-0.105$

$-0.251$

(0.177)

0.027

(0.07)

0.05

$-0.065$

(0.107)

(0.113)

0.025

0.08

(0.058)

0.1

(0.09)

$0.144^{* * *}$

(0.088)

(0.1)

(0.155) (0.088)

$(0.051)$

0.277

\begin{tabular}{c|cccc}
0.33 & 0.277 & $1.537 * * *$ & $1.28 * * *$ & 0.329 \\
$(0.391)$ & $(0.199)$ & $(0.214)$ & $(0.344)$ & $(0.39)$
\end{tabular}

Inject

$0.278 \quad 1.541 * * * \quad 1.283 * * *$

$\begin{array}{lll}(0.199) & (0.214) \quad(0.345)\end{array}$ $(0.391)$

$(0.199) \quad(0.214) \quad(0.344)$

(0.39)

$*, * *$, and $* * *$ indicate statistical significance at $<10 \%,<5 \%$, and $<1 \%$ levels, respectively.

Robust standard errors are in parentheses.

Sample size is 400 in the upper panel models and 176 in the lower panel models. 


\section{References}

Ayres, Ian, and Donohue, John J.III, 2000, "Shooting Down the More Guns, Less Crime Hypothesis," NBER Working Paper No. W9336.

Allgood, Sam, Mustard, David B., and Warren, Ronald S. Jr., 1999, "The Impact of Youth Criminal Behavior on Adult Earnings,"

Almond, Douglas, Chay, Kenneth Y., and Lee, David S., 2002, "Does Low Birth Weight Matter? Evidence from the U.S. Population of Twin Births," University of California, Berkeley, Center for Labor Economics Working Paper No. 53.

Ashenfelter, Orley, and Krueger, Alan, 1994, "Estimates of the Economic Returns to Schooling from a New Sample of Twins," American Economic Review, 84(5): 1157 1173.

Ashenfelter, Orley, and Zimmerman, David J., 1997, "Estimates of the Returns to Schooling From Sibling Data: Fathers, Sons, and Brothers," The Review of Economics and Statistics, 79(1):1-9.

Behrman, Jere R, Rosenzweig, Mark R., and Taubman, Paul, 1994, "Endowments and the Allocation of Schooling in the Family and in the Marriage Market: The Twins Experiment," The Journal of Political Economy, 102(6):1131-1174.

Behrman, Jere R, Rosenzweig, Mark R., and Taubman, Paul, 1996, “ College Choice and Wages: Estimates Using Data on Female Twins," The Review of Economics and Statistics, 78(1):672-685.

Blau, David, and Hagu, Alison, 1998, “The Demand for Quality in Child Care,” Journal of Political Economy, 106(1): 107-146.

Blumstein, Alfred, 1995, "Youth Violence, Guns, and the Illicit-Drug Industry," Journal of Criminal Law and Criminology, 86(1): 10-36.

Bound, John, and Freeman, Richard B., 1992, "What Went Wrong? The Erosion of Relative Earnings and Employment Among Young Black Men in the 1980s," Quarterly Journal of Economics, 107(1): 201-232.

Case, Anne C., and Katz, Lawrence F., 1991, “The Company You Keep: The Effects of Family and Neighborhood on Disadvantaged Youths," NBER Working Paper No. 3705

Chaiken, J. M. and M. R. Chaiken, 1990, "Drugs and Predatory Crime" in Drug and Crime M. Tonry and J. Q. Wilson (eds.), Chicago, University of Chicago Press.

Cook, Philip and Ludwig, Jens, 2002, "The Effects of Gun Prevalence on Burglary: Deterrence vs. Inducement,” NBER Working Paper No. 8926.

Cook, Philip and Ludwig, Jens, 1996, Guns in America: Results of a Comprehensive National Survey on Firearms Ownership and Use, Washington, The Policy Foundation. 
Corman, Hope and H. Naci Mocan, 2000, "A Time-Series Analysis of Crime, Deterrence, and Drug Abuse in New York City,” American Economic Review, 90(3): 584-604.

Corman, Hope and H. Naci Mocan, 2002, "Carrots, Sticks and Broken Windows," NBER Working Paper No. W9061.

Currie, Janet and Moretti, Enrico,2002, “Mother's Education and the Intergenerational Transmission of Human Capital: Evidence from College Openings and Longitudinal Data," NBER Working Paper No. W9330

Donohue, John III., and Levitt, Steven, 1998, "Guns, Violence, and the Efficiency of Illegal Markets," American Economic Review, 88(2): 463-67.

Duggan, Mark, 2001, “More Guns, More Crime," Journal of Political Economy, 109(5): 1086-1114.

Ehrlich, Isaac, 1973, "Participation in Illegitimate Activities: A Theoretical and Empirical Investigation," Journal of Political Economy, 81(3): 521-565.

Freeman, Richard B. and William M. Rodgers III, 2000, "Area Economic Conditions and the Labor Market Outcomes of Young Men in the 1990s Expansion," in Prosperity for All? The Economic Boom and African Americans; Robert Cherry and William M. Rodgers (eds.), NY: Russell Sage Foundation.

Glaeser, Edward L., Sacerdote, Bruce, and Jose A, Scheinkman, 1996, "Crime and Social Interactions," Quarterly Journal of Economics, 111(2): 507-548.

Gould, Eric D., David B. Mustard and Bruce A. Weinberg, 2002, "Burglary Rates and Local Labor Market Opportunities in the United States: 1977-1997," The Review of Economics and Statistics, 84 (1).

Griliches, Zvi and Jerry Hausman, 1990, "Errors in Variables in Panel Data," Journal of Econometrics, 31: 93-118.

Grogger, Jeff, and Willis, Michael, 2000, "The Emergence of Crack Cocaine and the Rise in Urban Crime Rates," The Review of Economics and Statistics, 82(4): 519-529.

Grossman, Michael, Kaestner, Robert, and Markowitz, Sara, 2002, "Get High and Get

Stupid: The Effect of Alcohol and Marijuana Use on Teen Sexual Behavior," NBER Working Paper No. 9216.

Goldstein, P. 1985, "The Drugs/Violence Nexus: A Tripartite Conceptual Framework," Journal of Drug Issues, 15(4): 493-506

Gruber, Jonathan (ed.) 2001, "Risky Behavior Among Youths,” Chicago and London, University of Chicago Press.

Jofre-Bonet, Mereia and Sindelar, Jody L., 2002, "Drug Treatment as a Crime Fighting Tool,” NBER Working Paper No. W 9038. 
Johnson, Mark E., Fisher, Dennis G., et, al, 2000, “ Reliability an Validity of Not-inTreatment Drug Users' Follow-Up Self-Reports” Aids and Behavior, 4(4): 373-80

Harrison, L. D., 1992, “The Drug-Crime Nexus in the USA,” Contemporary Drug Problems, 19(2): 203-246

Hu, Wei Yin, 1999, “Child Support, Welfare Delinquency, and Woman's Labor Supply,” Journal of Human Resources, 34(1): 71-103.

Kann, Laura, Charles W. Warren, William A. Harris et, al, 1995, "Youth Risk Behavior Surveillance - United States, 1993," Morbidity and Mortality Weekly Report 44: 155.

Levitt, Steven D., Lochner, Lance J., 2001 "The Determinants of Juvenile Crime," in Risky Behavior Among Youths: An Economic Analysis, J. Gruber (ed.), University of Chicago Press: Chicago, 2001.

Levitt, Steven D., 1999, “The Effect of Prison Population Size on Crime Rates: Evidence from Prison Overcrowding Litigation.” The Quarterly Journal of Economics, 111(2), p319-351, May.

Levitt, Steven D., 1998a,"Why Do Increased Crime Arrest Rates Appear to Reduce Crime: Deterrence, Incapacitation, or Measurement Error?" Economic Inquiry, Vol. 36(3):353-372.

Levitt, Steven D., 1998b, “Juvenile Crime and Punishment." Journal of Political Economy, Vol 106(6):1156-1185

Lott, John R. Jr. and David B. Mustard, 1997, "Crime, Deterrence, and Right-to-Carry Concealed Handguns", The Journal of Legal Studies, 26(1): 1-68.

Lott, John, 2000, "More Guns, Less Crime” $2^{\text {nd }}$ ed. Chicago: University of Chicago Press.

Lott, John R, and Whitley, John E., 2001, "Safe-Storage Guns Laws: Accidental Deaths, Suicides and Crime," Journal of Law and Economics, 44: 659-689.

Ludwig, Jens, and Cook Philip, 2000, "Homicide and Suicide Rate Associated With Implementation of the Brady Handgun Violence Prevention Act," Journal of American Medical Association, 284(5): 585-91.

Markowitz, Sara, 2000, “An Economic Analysis of Alcohol, Drugs, and Violent Crime in the National Crime Victimization Survey,” NBER Working Paper No. W7982.

Marvell, Thomas B., 2001, “The Impact of Banning Juvenile Gun Possession” Journal of Law and Economics, 44: 691-713.

Miller, Paul, and Mulvey, Charles, and Martin Nick, 1995, "What Do Twins Studies Reveal About the Economic Returns to Education? A Comparison of Australian U.S Findings," American Economic Review, 85(3): 586-599. 
Mocan, Naci H., Billups, Stephen, and Overland, Jody, 2000, “ A Dynamic Model of Differential Human Capital and Criminal Activity", NBER Working Paper No. W7584.

Mocan, Naci H., and Corman, Hope, 1998, "An Economic Analysis of Drug Use and Crime," Journal of Drug Issues, 28(3):613-29.

Mocan, Naci H., and Rees, Daniel, 1999, "Economic Conditions, Deterrence, and Juvenile Crime: Evidence from Micro Data" NBER Working Paper No. W7505.

Mocan, Naci H., Tekin, Erdal, and Zax, Jeffrey S., 2000, “The Demand for Medical Care in Urban China,” NBER Working Paper No. 7673.

Mocan, Naci H., and Tekin, Erdal, 2003, "Nonprofit Sector and Part-Time Work: An Analysis of Employer-Employee Matched Data of Child Care Workers," Review of Economics and Statistics, 85:1, pp. 38-50.

Mustard, David B., 2001, "The Impact of Gun Laws on police Deaths," Journal of Law and Economics, 44: 635-657.

National Vital Statistics Report, 1999; Vol 47, No: 24; National Center for Health Statistics, Hyattsville, Maryland.

Parker, Jeffrey S., 2001, " Guns, Crime, and Academics: Some Reflections on the Gun Control Debate," Journal of Law and Economics, 44: 715-723.

Raphael, Steven and Rudolf Winter-Ebmer, 2001," Identifying the Effect of Unemployment on Crime," The Journal of Law and Economics, 44: 259-83.

Smith, Tom W., 2000, 1999 National Gun Policy Survey of the National Opinion Research Center: Research Finding, NORC, University of Chicago

Soler, Mark, 2001, "Public Opinion on Youth, Crime and Race: A Guide for Advocates."

Ventura, Stephanie, Martin, Joyce, etc., 2001, "Births Final Data for 1999” in National Vital Statistics Reports, 49(1).

Weiss, Roger D., Najavits, Lisa M., et. al., 1998, "Validity of Substance Use Self-Reforts in Dually Diagnosed Outpatients,” American Journal of Psychiatry, 155(1): 127-128.

Wintemute, Garen, 2000, "Guns and Gun Violence" in The Crime Drop in America, Alfred Blumshtein, and Joel Wallman (eds.), NY, Cambridge University Press.

Wilson, James Q., and Petersilia Joan (eds.), 1995, Crime; San Francisco, California: ICS Press, Institute for Contemporary Studies. 


\section{APPENDIX-A}

\section{General Framework}

$\mathrm{DR}_{\mathrm{it}}=\mathrm{DR}^{*}{ }_{\text {it }}+\mathrm{v}_{\mathrm{it}}$, where $\mathrm{DR}^{*}{ }_{\mathrm{it}}$ is the actual drug use $(0=\mathrm{No}, 1=\mathrm{Yes})$ and $\mathrm{DR}_{\mathrm{it}}$ is the reported drug use $(0=$ No, $1=$ Yes $)$

Let probability distribution of $\mathrm{v}_{\text {it }}$ be

$\operatorname{Prob}\left(\mathrm{DR}_{\mathrm{it}}=1, \mathrm{DR}^{*}{ }_{\mathrm{it}}=1\right)=\mathrm{p}_{1}$

$\operatorname{Prob}\left(\mathrm{DR}_{\mathrm{it}}=1, \mathrm{DR}^{*}{ }_{\mathrm{it}}=0\right)=0$

$\operatorname{Prob}\left(\mathrm{DR}_{\mathrm{it}}=0, \mathrm{DR}^{*}{ }_{\mathrm{it}}=0\right)=\mathrm{p}_{2}$

$\operatorname{Prob}\left(\mathrm{DR}_{\mathrm{it}}=0, \mathrm{DR}^{*}{ }_{\mathrm{it}}=1\right)=\mathrm{q}$

In other words,

\begin{tabular}{|c|c|c|c|}
\hline $\mathrm{DR}_{\text {it }}$ & $\mathrm{DR}^{*}{ }_{\text {it }}$ & $\mathrm{v}_{\text {it }}$ & Prob $\left(\mathrm{v}_{\text {it }}\right)$ \\
\hline 1 & 1 & 0 & $\mathrm{P}_{1}$ \\
\hline 1 & 0 & 1 & 0 \\
\hline 0 & 0 & 0 & $\mathrm{P}_{2}$ \\
\hline 0 & 1 & -1 & $\mathrm{q}$ \\
\hline
\end{tabular}

$\mathrm{p}_{1}+\mathrm{p}_{2}+\mathrm{q}=1$

$E[v]=-q$

$E\left[D R^{*}\right]=1-p_{2}$

$\operatorname{var}[v]=q-q^{2}$

$\operatorname{var}\left[D R^{*}\right]=p_{2}-p_{2}^{2}$

$\operatorname{cov}\left[v, D R^{*}\right]=-p_{2} q$

$\operatorname{var}[D R]=p_{1}-p_{1}^{2}$

\section{Probability Limit of the Coefficient of Drug Use in First-differenced Data}

The probability limit is

$p \lim \hat{\beta}=\beta \frac{\operatorname{var}\left[\Delta D R_{t}{ }^{*}\right]+\operatorname{cov}\left[\Delta v_{t}, \Delta D R_{t}{ }^{*}\right]}{\operatorname{var}\left[\Delta D R_{t}\right]}$

Note that by definition

$$
\operatorname{var}\left[\Delta D R_{t}^{*}\right]=\operatorname{var}\left[\Delta D R_{t}\right]-\operatorname{var}\left[\Delta v_{t}\right]-2 \operatorname{cov}\left[\Delta D R_{t}^{*}, \Delta v_{t}\right]
$$

Thus,

$\operatorname{cov}\left[\Delta D R_{t}^{*}, \Delta v_{t}\right]=\frac{1}{2} \operatorname{var}\left[\Delta D R_{t}\right]-\frac{1}{2} \operatorname{var}\left[\Delta v_{t}\right]-\frac{1}{2} \operatorname{var}\left(\Delta D R_{t}^{*}\right)$ 
Substitution for $\operatorname{cov}\left(\Delta \mathrm{DR}{ }^{*}, \Delta \mathrm{v}\right)$ provides

$p \lim \hat{\beta}=\beta \frac{0.5\left[\operatorname{var}\left(\Delta D R_{t}\right)+\operatorname{var}\left(\Delta D R^{*}{ }_{t}\right)-\operatorname{var}\left(\Delta v_{t}\right)\right]}{\operatorname{var}\left(\Delta D R_{t}\right)}$

Note that

$\operatorname{var}\left(\Delta D R_{t}\right)=\operatorname{var}\left(D R_{t}-D R_{t-1}\right)=\operatorname{var}\left(D R_{t}\right)+\operatorname{var}\left(D R_{t-1}\right)-2 \operatorname{cov}\left(D R_{t}, D R_{t-1}\right)$

Assuming that $D R$ is covariance stationary; i.e. $\operatorname{Var}\left(D R_{t}\right)=\operatorname{Var}\left(D R_{t-1}\right)$, $\operatorname{var}\left(\Delta D R_{t}\right)=2 \sigma_{D R}^{2}\left(1-\rho_{D R_{t}, D R_{t-1}}\right)$, where $\sigma_{\mathrm{DR}}^{2}=\operatorname{var}\left(\mathrm{DR}_{\mathrm{t}}\right)$.

Similarly

$\operatorname{var}\left(\Delta D *_{t}{ }_{t}\right)=2 \sigma_{D R^{*}}^{2}\left(1-\rho_{D R_{t}^{*}, D R^{*}{ }_{t-1}}\right) \quad$ and $\quad \operatorname{var}\left(\Delta v_{t}\right)=2 \sigma_{V}^{2}\left(1-\rho_{v_{t} v_{t-1}}\right)$

where $\sigma_{v}^{2}=\operatorname{var}\left(v_{t}\right)$ and $\sigma^{2}{ }_{D R}^{*}=\operatorname{var}\left(D_{t}^{*}\right)$

Substituting the variances of DR, DR ${ }^{*}$ and $v$ into the probability limit formula, one obtains

$$
p \lim \hat{\beta}=\beta \frac{0.5\left[2 \sigma_{D R}^{2}\left(1-\rho_{D R_{t}, D R_{t-1}}\right)+2 \sigma_{D R^{*}}^{2}\left(1-\rho_{D R_{t}^{*}, D R^{*} t-1}\right)-2 \sigma_{v}^{2}\left(1-\rho_{v_{t}, v_{t-1}}\right)\right]}{2 \sigma_{D R}^{2}\left(1-\rho_{D R_{t}, D R_{t-1}}\right)}
$$

Note that

$$
\begin{aligned}
& A 2=\operatorname{cov}\left(D R_{t}, D R_{t-1}\right)=\operatorname{cov}\left(D *_{t}{ }_{t}+v_{t}, D R_{t-1}+v_{t-1}\right) \\
& =\operatorname{cov}\left(D R_{t}, D R_{t-1}\right)=\operatorname{cov}\left(D *_{t}, D *_{t-1}\right)+\operatorname{cov}\left(D R_{t-1}, v_{t}\right)+\operatorname{cov}\left(D *_{t}, v_{t-1}\right)+\operatorname{cov}\left(v_{t}, v_{t-1}\right)
\end{aligned}
$$

Also,

$$
\begin{aligned}
& \operatorname{cov}\left(D R_{t}, D R_{t-1}\right)=\rho_{D R_{t}, D R_{t-1}} \sigma_{D R}^{2} \\
& \operatorname{cov}\left(D R^{*}, D R^{*}{ }_{t-1}\right)=\rho_{D R^{*}, D R^{*} t-1} \sigma_{D R^{*}}^{2} \\
& \operatorname{cov}\left(v_{t}, v_{t-1}\right)=\rho_{v_{t}, v_{t-1}} \sigma_{v}^{2}
\end{aligned}
$$

Therefore, one can rewrite (A2) as

$$
\rho_{D R_{t}, D R_{t-1}} \sigma_{D R}^{2}=\rho_{D R_{t}^{*}, D R^{*}{ }_{t-1}} \sigma_{D R^{*}}^{2}+\rho_{v_{t}, v_{t-1}} \sigma_{v}^{2}+\operatorname{cov}\left(D *_{t-1}, v_{t}\right)+\operatorname{cov}\left(D *_{t}, v_{t-1}\right)
$$

Because, $\operatorname{cov}\left(D R^{*}{ }_{t-1}, v_{t}\right)=\operatorname{cov}\left(D *^{*}{ }_{t-1}, D R_{t}-D R_{t}\right)=\operatorname{cov}\left(D R_{t-1}, D R_{t}\right)-\operatorname{cov}\left(D R^{*}{ }_{t-1}, D R_{t}{ }_{t}\right)$.

Assuming $\operatorname{cov}\left(D R^{*}{ }_{t-1}, D R_{t}\right)=0$, one obtains $\operatorname{cov}\left(D R^{*}{ }_{t-1}, v_{t}\right)=-\rho_{D R^{*}, D R^{*}{ }_{t-1}} \sigma_{D R^{*}}^{2}$ 
Similarly.

$\operatorname{cov}\left(D R_{t}^{*}, v_{t-1}\right)=\operatorname{cov}\left(D R^{*}, D R_{t-1}-D R^{*}{ }_{t-1}\right)=\operatorname{cov}\left(D R_{t}^{*}, D R_{t-1}\right)-\operatorname{cov}\left(D R^{*}, D R_{t}^{*}{ }_{t-1}\right)$

Assuming

$\operatorname{cov}\left(D R^{*}, D R_{t-1}\right)=0$

one gets

$\operatorname{cov}\left(D R^{*}, v_{t-1}\right)=-\rho_{D R_{t}^{*}, D R^{*}-1} \sigma_{D R^{*}}^{2}$

Therefore, (A2) is equivalent to:

$$
\begin{aligned}
& \rho_{D R_{t}, D R_{t-1}} \sigma_{D R}^{2}=\rho_{D R^{*}, D R^{*} t-1} \sigma_{D R^{*}}^{2}+\rho_{v_{t}, v_{t-1}} \sigma_{v}^{2}-\rho_{D R^{*}, D R^{*} t-1} \sigma_{D R^{*}}^{2}-\rho_{D R^{*}, D R^{*}{ }_{t-1}} \sigma_{D R^{*}}^{2} \\
& \rho_{D R_{t}, D R_{t-1}} \sigma_{D R}^{2}=\rho_{v_{t}, v_{t-1}} \sigma_{v}^{2}-\rho_{D R_{t}^{*}, D R^{*}{ }_{t-1}} \sigma_{D R^{*}}^{2}
\end{aligned}
$$

Solving for $\rho_{v t, v t-1}$ yields

(A3)

$\rho_{v_{t}, v_{t-1}}=\frac{\rho_{D R_{t}, D R_{t-1}} \sigma_{D R}^{2}+\rho_{D R_{t}^{*}, D R^{*}{ }_{t-1}} \sigma_{D R^{*}}^{2}}{\sigma_{v}^{2}}$

Substitution of (A3) into (A1) gives

$$
p \lim \hat{\beta}=\beta \frac{0.5\left[2 \sigma_{D R}^{2}\left(1-\rho_{D R_{t}, D R_{t-1}}\right)+2 \sigma_{D R^{*}}^{2}\left(1-\rho_{D R^{*}, D R^{*}}\right)-2 \sigma_{v}^{2}\left(1-\frac{\rho_{D R_{t}, D R_{t-1}} \sigma_{D R}^{2}+\rho_{D R^{*}, D R^{*}} \sigma_{t-1}^{2}}{\sigma_{v R^{*}}^{2}}\right)\right]}{2 \sigma_{D R}^{2}\left(1-\rho_{D R_{t}, D R_{t-1}}\right)}
$$

Simplification yields

$p \lim \hat{\beta}=\beta \frac{\sigma_{D R}^{2}+\sigma_{D R^{*}}^{2}-\sigma_{v}^{2}}{2 \sigma_{D R}^{2}\left(1-\rho_{D R_{t}, D R_{t-1}}\right)}=\frac{p_{1} p_{2}}{\left(p_{1}-p_{1}^{2}\right)\left(1-\rho_{D R_{t}, D R_{t-1}}\right)}$

Therefore

$$
p \lim \hat{\beta}=\beta \frac{p_{1} p_{2}}{\left(p_{1}-p_{1}^{2}\right)\left(1-\rho_{D R_{t}, D R_{t-1}}\right)}
$$

\section{Probability Limit of the Coefficient of Drug Use in Double-differenced Data}

The probability limit is

$$
p \lim \hat{\beta}=\beta \frac{\operatorname{var}\left(\nabla \Delta D R_{j i t}{ }^{*}\right)+\operatorname{cov}\left(\nabla \Delta v_{j i t}, \nabla \Delta D R_{j i t}{ }^{*}\right)}{\operatorname{var}\left(\nabla \Delta D R_{j i t}\right)}
$$


By definition, $\operatorname{var}\left(\nabla \Delta D R_{j i t}{ }^{*}\right)=\operatorname{var}\left(\nabla \Delta D R_{j i t}\right)-\operatorname{var}\left(\nabla \Delta v_{j i t}\right)-2 \operatorname{cov}\left(\nabla \Delta D R_{j i t} *, \nabla \Delta v_{j i t}\right)$

Therefore,

$$
\operatorname{cov}\left(\nabla \Delta D R_{j i t}^{*}, \nabla \Delta v_{j i t}\right)=\frac{1}{2} \operatorname{var}\left(\nabla \Delta D R_{j i t}\right)-\frac{1}{2} \operatorname{var}\left(\nabla \Delta v_{j i t}\right)-\frac{1}{2} \operatorname{var}\left(\nabla \Delta D R_{j i t}{ }^{*}\right)
$$

and

$$
p \lim \hat{\beta}=\beta \frac{0.5\left\lfloor\operatorname{var}\left(\nabla \Delta D R_{j i t}\right)+\operatorname{var}\left(\nabla \Delta D R_{j i t}^{*}\right)-\operatorname{var}\left(\nabla \Delta v_{j i t}\right)\right\rfloor}{\operatorname{var}\left(\nabla \Delta D R_{j i t}\right)}
$$

Note that

$$
\begin{aligned}
& \operatorname{var}\left(\nabla \Delta D R_{j i t}\right)=\operatorname{var}\left(D R_{j 2 t}-D R_{j 2 t-1}-D R_{j 1 t}+D R_{j 1 t-1}\right)=\operatorname{var}\left(D R_{j 2 t}\right)+\operatorname{var}\left(D R_{j 2 t-1}\right)+\operatorname{var}\left(D R_{j 1 t}\right)+\operatorname{var}\left(D R_{j 1 t-1}\right) \\
& -2 \operatorname{cov}\left(D R_{j 2 t}, D R_{j 2 t-1}\right)-2 \operatorname{cov}\left(D R_{j 2 t}, D R_{j 1 t}\right)+2 \operatorname{cov}\left(D R_{j 2 t}, D R_{j 1 t-1}\right)+2 \operatorname{cov}\left(D R_{j 2 t-1}, D R_{j 1 t}\right)-2 \operatorname{cov}\left(D R_{j 2 t-1}, D R_{j 1 t-1}\right) \\
& -2 \operatorname{cov}\left(D R_{j 1 t}, D R_{j 1 t-1}\right)
\end{aligned}
$$

where the subscripts 1 and 2 represent the first and the second individuals in sibling (twin) pair $j$, and $t-1$ and $t$ represent the first and the second time periods. Suppressing $j$ for ease of notation, we can rewrite the above equation as

$$
\begin{aligned}
& \operatorname{var}\left(\nabla \Delta D R_{i t}\right)=4 \sigma_{D R}^{2}-2 \rho_{D R_{2 t} D R_{2 t-1}} \sigma_{D R}^{2}-2 \rho_{D R_{2 t} D R_{1 t}} \sigma_{D R}^{2}+2 \rho_{D R_{2 t} D R_{1 t-1}} \sigma_{D R}^{2}+2 \rho_{D R_{2 t-1} D R_{1 t}} \sigma_{D R}^{2}- \\
& -2 \rho_{D R_{2 t-1} D R_{1 t-1}} \sigma_{D R}^{2}-2 \rho_{D R_{1 t} D R_{1 t-1}} \sigma_{D R}^{2}
\end{aligned}
$$

Assuming constant variances of drug use between siblings and over time, one obtains

$$
\operatorname{var}\left(\nabla \Delta D R_{i t}\right)=\sigma_{D R}^{2}(\Phi+4)
$$

where $(\mathrm{A} 5)=\Phi=-2 \rho_{D R_{2 t} D R_{2 t-1}}-2 \rho_{D R_{2 t} D R_{1 t}}+2 \rho_{D R_{2 t} D R_{1 t-1}}+2 \rho_{D R_{2 t-1} D R_{1 t}}-2 \rho_{D R_{2 t-1} D R_{1 t-1}}-2 \rho_{D R_{1 t} D R_{1 t-1}}$

Similarly, $\operatorname{var}\left(\nabla \Delta D R^{*}{ }_{i t}\right)=\sigma_{D R^{*}}^{2}(\Psi+4)$

where

$$
\Psi=-2 \rho_{D R^{*}{ }_{t} D R^{*}{ }_{2 t-1}}-2 \rho_{D R^{*}{ }_{2 t} D R^{*}{ }_{1 t}}+2 \rho_{D R^{*}{ }_{2 t} D R^{*}{ }_{t t-1}}+2 \rho_{D R^{*}{ }_{2 t-1} D R^{*}{ }_{t t}}-2 \rho_{D R^{*}{ }_{2 t-1} D R^{*}{ }_{t t-1}}-2 \rho_{D R^{*}{ }_{1 t} D R^{*}{ }_{t t-1}}
$$

and, $\operatorname{var}\left(\nabla \Delta v_{i t}\right)=\sigma_{V}^{2}(\Omega+4)$

where

$$
\Omega=-2 \rho_{v_{2 t} v_{2 t-1}}-2 \rho_{v_{2 t} v_{1 t}}+2 \rho_{v_{2 t} v_{1 t-1}}+2 \rho_{v_{2 t-1} v_{1 t}}-2 \rho_{v_{2 t-1} v_{1 t-1}}-2 \rho_{v_{1 t} v_{1 t-1}}
$$


Substituting the expressions for the variances in (A4) gives

$p \lim \hat{\beta}=\beta \frac{\operatorname{var}\left(D R_{i t}^{*}\right)(4+\Psi)+\frac{1}{2}\left(\operatorname{var}\left(D R_{i t}\right)(4+\Phi)-\operatorname{var}\left(v_{i t}\right)(4+\Omega)-\operatorname{var}\left(D R_{i t}^{*}\right)(4+\Psi)\right.}{(4+\Phi) \operatorname{var}\left(D R_{i t}\right)}$

$p \lim \hat{\beta}=\beta \frac{1}{2} \frac{\left(\operatorname{var}\left(D R_{i t}\right)(4+\Phi)-\operatorname{var}\left(v_{i t}\right)(4+\Omega)+\operatorname{var}\left(D R_{i t}{ }^{*}\right)(4+\Psi)\right.}{\operatorname{var}\left(D R_{i t}\right)(4+\Phi)}$

Note that

$$
\begin{aligned}
& \operatorname{cov}\left(D R_{1 t}, D R_{2 t-1}\right)=\operatorname{cov}\left(D R^{*}{ }_{1 t}+v_{1 t}, D R^{*}{ }_{2 t-1}+v_{2 t-1}\right) \\
& \operatorname{cov}\left(D R_{1 t}, D R_{2 t-1}\right)=\operatorname{cov}\left(D R^{*}{ }_{1 t}, D *^{*}{ }_{1 t}\right)+\operatorname{cov}\left(D *^{*}{ }_{1 t}, v_{1 t}\right)+\operatorname{cov}\left(v_{2 t-1}, D R^{*}{ }_{2 t-1}\right)+\operatorname{cov}\left(v_{2 t-1}, v_{2 t-1}\right)
\end{aligned}
$$

\section{Because}

$$
\begin{aligned}
& \operatorname{cov}\left(D R_{1 t}, D R_{2 t-1}\right)=\rho_{D R_{1 t}, D R_{2 t-1}} \sigma_{D R}^{2} \\
& \operatorname{cov}\left(D R^{*}{ }_{1 t}, D R^{*}{ }_{2 t-1}\right)=\rho_{D R^{*}{ }_{t}, D R^{*}{ }_{2 t-1}} \sigma_{D R^{*}}^{2} \\
& \operatorname{cov}\left(v_{1 t}, v_{2 t-1}\right)=\rho_{1 t}, v_{2 t-1 s} \sigma_{v}^{2}
\end{aligned}
$$

We obtain

$(\mathrm{A} 6)=\operatorname{Cov}\left(\mathrm{DR}_{1 \mathrm{t}}, \mathrm{DR}_{2 \mathrm{t}-1}\right)=$

$\rho_{D R_{1 t}, D R_{2 t-1}} \sigma_{D R}^{2}=\rho_{D R^{*}{ }_{1 t}, D R^{*}{ }_{2 t-1}} \sigma_{D R^{*}}^{2}+\rho_{v_{1 t}, v_{2 t-1}} \sigma_{v}^{2}+\operatorname{cov}\left(D *^{*}, v_{2 t-1}\right)+\operatorname{cov}\left(v_{1 t}, D R^{*}{ }_{2 t-1}\right)$

The third term in Equation (A6) is:

$\operatorname{cov}\left(D R *_{1 t}, v_{2 t-1}\right)=\operatorname{cov}\left(D R^{*}, D R_{2 t-1}-D R^{*}{ }_{2 t-1}\right)=\operatorname{cov}\left(D R^{*}{ }_{1 t}, D R_{2 t-1}\right)-\operatorname{cov}\left(D R^{*}, D R^{*}{ }_{2 t-1}\right)$

Assuming $\operatorname{cov}\left(D R^{*}{ }_{1 t}, D R_{2 t-1}\right)=0$ we obtain

$(\mathrm{A} 7)=\operatorname{cov}\left(D R^{*}{ }_{1 t}, v_{2 t-1}\right)=-\operatorname{cov}\left(D R^{*}{ }_{1 t}, D R^{*}{ }_{2 t-1}\right)=-\rho_{D R^{*} t, D *^{*} t-1} \sigma_{D R^{*}}^{2}$

The fourth term in Equation (A6) is:

$\operatorname{cov}\left(v_{1 t}, D R^{*}{ }_{2 t-1}\right)=\operatorname{cov}\left(D R_{1 t}-D *^{*}, D R^{*}{ }_{2 t-1}\right)=\operatorname{cov}\left(D R_{1 t}, D R^{*}{ }_{2 t-1}\right)-\operatorname{cov}\left(D R^{*}, D R{ }^{*}{ }_{2 t-1}\right)$

Again, assuming $\operatorname{cov}\left(D R_{1 t}, D R^{*}{ }_{2 t-1}\right)=0$ we obtain

$(\mathrm{A} 8)=\operatorname{cov}\left(v_{1 t}, D R^{*}{ }_{2 t-1}\right)=-\operatorname{cov}\left(D R^{*}{ }_{1 t}, D R^{*}{ }_{2 t-1}\right)=-\rho_{D R^{*} t}, D R^{*}{ }_{2 t-1} \sigma_{D R^{*}}^{2}$

Substituting (A7) and (A8) into (A6) one obtains

$\rho_{D R_{1 t}, D R_{2 t-1}} \sigma_{D R}^{2}=-\rho_{D R^{*}{ }_{1 t}, D R^{*}{ }_{2 t-1}} \sigma_{D R^{*}}^{2}+\rho_{v_{1 t}, v_{2 t-1}} \sigma_{v}^{2}$ 
or

$\rho_{D R_{1 t}, D R_{2 t-1}}=\frac{-\rho_{D R^{*}{ }_{l t}, D R^{*}{ }_{2 t-1}} \sigma_{D R^{*}}^{2}+\rho_{v_{1 t}, v_{2 t-1}} \sigma_{v}^{2}}{\sigma_{D R}^{2}}$

One can obtain similar expressions for

$\rho_{D R_{2 t} D R_{1 t}}, \rho_{D R_{2 t} D R_{1 t-1}} \rho_{D R_{2 t-1} D R_{1 t}}, \rho_{D R_{2 t-1} D R_{1 t-1}}, \rho_{D R_{1 t} D R_{1 t-1}}$.

Substituting each of these correlation coefficients into (A5) one obtains

$$
\begin{aligned}
& \Phi=\frac{\sigma_{v}^{2} \Omega-\sigma_{D R^{*}}^{2} \Psi}{\sigma_{D R}^{2}} \\
& \Omega=\frac{\sigma_{D R}^{2} \Phi+\sigma_{D R^{*}}^{2} \Psi}{\sigma_{v}^{2}}
\end{aligned}
$$

Substitution of $\Omega$ into (A4) gives

$p \lim \hat{\beta}=\beta \frac{1}{2} \frac{\left[\sigma_{D R}^{2}(4+\Phi)-\sigma_{v}^{2}\left(4+\frac{\sigma_{D R}^{2} \Phi+\sigma_{D R^{*}}^{2} \Psi}{\sigma_{v}^{2}}\right)+\sigma_{D R^{*}}^{2}(4+\Psi)\right]}{\sigma_{D R}^{2}(4+\Phi)}$

which simplifies to

$p \lim \hat{\beta}=\beta \frac{2\left[\sigma_{D R}^{2}-\sigma_{v}^{2}+\sigma_{D R^{*}}^{2}\right]}{\sigma_{D R}^{2}(4+\Phi)}$

Substituting the expressions for variances one obtains

$p \lim \hat{\beta}=\beta \frac{4 p_{1} p_{2}}{\left(p_{1}-p_{1}^{2}\right)(4+\Phi)}$ 


\section{APPENDIX-B}

To address potential reverse-causality, we specify Equations (A7) and (A8) below.

(A7) $\quad \nabla \Delta \mathrm{CR}_{\mathrm{jit}}=\delta \nabla \Delta \mathrm{X}_{\mathrm{jit}}+\beta \nabla \Delta \mathrm{DR}_{\mathrm{jit}}+\mu_{\mathrm{jit}}$

(A8) $\nabla \Delta \mathrm{DR}_{\mathrm{jit}}=\pi \nabla \Delta \mathrm{X}_{\mathrm{jit}}+\zeta \nabla \Delta \mathrm{Z}_{\mathrm{jit}}+\eta_{\mathrm{jit}}$

In Equation (A8) $\mathrm{Z}$ represents the instruments that impact the drug use of the juvenile which include the following variables: whether at least one of the three best friends smokes at least one cigarette a day, whether at least one of the three best friends drinks alcohol at least once a month, and whether at least one of the three best friends uses marijuana at least once a month. While it can plausibly be argued that friends' consumption of cigarette, alcohol and marijuana may be correlated with own drug use, it is less obvious that these instruments are uncorrelated with own criminal activity. Unfortunately no better instruments are available. State or county level alcohol and drug prices are not viable candidates to identify the effect of drug use as they do not vary between siblings and twins. School based policy variables are not useful either, because all twins and most siblings attend the same school. ${ }^{24}$

Equations (A7) and (A8) are estimated jointly using full information maximum likelihood. We allow for a correlation between the error terms in equations (A7) and (A8) using the discrete factor method (DFM). The DFM assumes that the correlation between these two equations is governed by a common factor, the distribution of which can be approximated by a step function. The common discrete factor is then integrated out of the model as in the standard random effects approach. This method is less restrictive than the specifying functional form, such as joint normality. See Blau and Hagy (1998), Hu (1999), Mocan, Tekin, and Zax (2000), and Mocan and Tekin (2003) for applications of the DFM. 
Table A-1

The Impact of Drug Use on Crime with Reverse Causality

Full Information Maximum Likelihood Estimates of Drug Use

\begin{tabular}{cccccc}
\hline & & \multicolumn{3}{c}{ Without Measurement Error Correction } \\
\cline { 3 - 5 } & & Robbery & Burglary & Theft & Damage \\
\hline \multirow{4}{*}{ All Siblings } & Inhale & 0.136 & $0.179^{*}$ & $0.196^{*}$ & $0.176^{*}$ \\
& & $(0.095)$ & $(0.095)$ & $(0.095)$ & $(0.095)$ \\
& Inject & $0.401^{*}$ & $0.515^{*}$ & 0.768 & $0.424^{*}$ \\
& & $(0.264)$ & $(0.264)$ & $(0.264)$ & $(0.264)$ \\
\hline \multirow{3}{*}{ All Twins } & Inhale & 0.064 & 0.137 & 0.128 & 0.096 \\
& & $(0.179)$ & $(0.179)$ & $(0.18)$ & $(0.18)$ \\
& Inject & -0.124 & 0.648 & $0.963^{*}$ & 0.091 \\
Identical Twins & $(0.523)$ & $(0.523)$ & $(0.523)$ & $(0.523)$ \\
& & -0.003 & 0.071 & -0.133 & -0.206 \\
& Inhale & & $(0.336)$ & $(0.335)$ & $(0.335)$ \\
& & $(0.338)$ & $1.552^{*}$ & $1.399^{*}$ & 0.314 \\
& & 0.36 & $(0.885)$ & $(0.885)$ & $(0.885)$ \\
\hline
\end{tabular}

\begin{tabular}{|c|c|c|c|c|c|}
\hline & \multicolumn{4}{|c|}{ With Measurement Error Correction } \\
\hline & & Robbery & Burglary & Theft & Damage \\
\hline \multirow{4}{*}{ All Siblings } & Inhale & 0.100 & $0.132 *$ & $0.144 *$ & $0.130^{*}$ \\
\hline & & $(0.07)$ & $(0.07)$ & $(0.07)$ & $(0.07)$ \\
\hline & Inject & $0.356^{*}$ & $0.457^{*}$ & 0.681 & $0.376^{*}$ \\
\hline & & $(0.234)$ & $(0.234)$ & $(0.234)$ & $(0.234)$ \\
\hline \multirow{4}{*}{ All Twins } & Inhale & 0.047 & 0.101 & 0.095 & 0.071 \\
\hline & & $(0.132)$ & $(0.132)$ & $(0.133)$ & $(0.133)$ \\
\hline & Inject & -0.124 & 0.647 & $0.961 *$ & 0.091 \\
\hline & & $(0.522)$ & $(0.522)$ & $(0.522)$ & $(0.522)$ \\
\hline \multirow{4}{*}{ Identical Twins } & Inhale & -0.002 & 0.044 & -0.082 & -0.128 \\
\hline & & $(0.21)$ & $(0.208)$ & $(0.208)$ & $(0.208)$ \\
\hline & Inject & 0.359 & $1.548 *$ & $1.396^{*}$ & 0.313 \\
\hline & & $(0.883)$ & $(0.883)$ & $(0.883)$ & $(0.883)$ \\
\hline
\end{tabular}

$*, * *$, and $* * *$ indicate statistical significance at $<10 \%,<5 \%$, and $<1 \%$ levels, respectively.

Robust standard errors are in parentheses.

${ }^{24}$ Grossman, Kaestner and Markowitz (2002) highlight the same point in their analysis of drug use on teenage sexual activity. 